\title{
CARACTERIZAÇÃO HIDRÁULICA DE UM TUBO GOTEJADOR
}

\author{
ANGELITA TERESINHA VIEIRA \\ Engenheiro Agrônomo
}

Orientador : Prof. Dr. José Antônio Frizzone

\begin{abstract}
Dissertação apresentada à Escola Superior de Agricultura "Luiz de Queiroz" da Universidade de São Paulo, para obtenção do Título de Mestre em Agronomia. Área de Concentração : Irrigação e Drenagem.
\end{abstract}

PIRACICABA

Estado de São Paulo - Brasil

Julho - 1996 
Dados Internacionais de Catalogação na Publicação (CIP)

DIVISÃO DE BIBLIOTECA E DOCUMENTAÇĀO - Campus “Luiz de Queiroz"/USP

Vieira, Angelita Teresinha

Caracterizaçāo hidráulica de um tubo gotejador / Angelita Teresinha Vieira. - -

Piracicaba, 1996.

56 p. : il.

Dissertação (mestrado) - - Escola Superior de Agricultura Luiz de Queiroz, 1996

Bibliografia.

1. Hidráulica agricola 2. Irrigação localizada 3. Tubo gotejador I. Titulo

CDD 631.7

631.3 


\title{
CARACTERIZAÇÃO HIDRÁULICA DE UM TUBO GOTEJADOR
}

\author{
ANGELITA TERESINHA VIEIRA
}

Aprovada em 12 de setembro de 1996

Comissão julgadora:

Prof. Dr. José Antônio Frizzone

Prof. Dr Tarlei Arriel Botrel

Prof. Dr João Carlos Cury Saad

\author{
ESALQ/USP \\ ESALQ/USP \\ UNESP/BOTUCATU
}

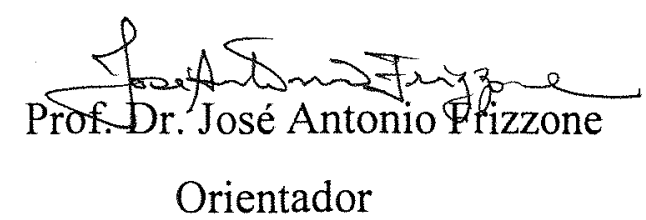


A pesson que através de seu amor, carinho, alegria, compreensão e auxílio, ajudou-me a superar mais facilmente todos os obstáculos, com amor especial, Forge A. M. Silveira

\section{OAEREÇO}

Aos meus pais, Bento $\mathcal{A}$. Vieira e Nilza $\mathcal{L}$. Vieira pelo amor e pela vida 


\section{AGRADECIMENTOS}

Ao Prof. Dr. José Antonio Frizzone, pela orientação e ensinamentos no decorrer do curso e no desenvolvimento de meu trabalho;

Ao Prof. Dr Tarlei Arriel Botrel, pela opinião dispensada com o trabalho de dissertação, através de seu conhecimento, auxiliando na solução de diversos problemas;

A Rain-Bird, na pessoa do Dr. Augusto F. R. Póvoa, pelo fornecimento de material para a realização dos ensaios;

A todos os professores dos Departamentos de Engenharia Rural e Física e Meteorologia pelos ensinamentos proferidos;

Ao curso de Pós-Graduação em Irrigação e Drenagem da ESALQ/USP, pela oportunidade a mim dispensada;

Aos funcionários do Departamento de Engenharia Rural, em especial a Antônio César Souza, Hélio Toledo Gomes e José Figueiredo, pela colaboração na montagem dos ensaios e amizade;

Ao Conselho Nacional de Desenvolvimento Científico e Tecnológico (CNPq) e Coordenação de Aperfeiçoamento e Pessoal de Nível Superior (CAPES), pela bolsa de estudos fornecida;

Ao colega Guilherme Miranda, Prof. Olívio José Soccol e Prof. Mário Nestor Ulmann do Centro de Ciências Agroveterinárias (CCAV)/UDESC pelo incentivo e apoio para a realização deste curso;

Aos colegas de curso Anderson Soares Pereira e Fernando Mendonça, pelo grande auxílio, dicas e tempo dispensados na discussões do meu trabalho; 
Aos demais colegas de curso que estiveram presentes através de sua amizade, ensinamentos, convivência, discussões, bate-papo e alegria contribuindo muito na minha formação;

Aos meus irmãos e cunhadas que estiveram sempre me apoiando e incentivando;

Acima de tudo a Deus por estar sempre presente durante cada momento de minha vida, guiando meu caminho. 


\section{SUMÁRIO}

LISTA DE FIGURAS

Página

LISTA DE TABELAS

vii

LISTA DE SÍMBOLOS

viii

RESUMO

ix

SUMMARY

xii

1. INTRODUÇÃO

xiv

2. REVISÃO DE LITERATURA …...................................................... 03

3. MATERIAL E MÉTODOS …........................................................ 21

3.1. Uniformidade de vazão …........................................................ 21

3.2. Relação vazão versus pressão ……................................................ 23

3.3. Variação do diâmetro com a pressão …………............................ 24

3.4. Resistência à pressão ................................................................ 24

3.5. Perda de carga ..................................................................... 25

3.6. Fator de redução de perda de carga (F) ...................................... 27

3.7. Dimensionamento de linhas laterais pelo método estatístico ....... $\quad 29$

4. RESULTADOS E DISCUSSÃO .................................................... 35

4.1. Uniformidade de vazão ......................................................... 35

4.2. Relação vazão versus pressão ...................................................... 36

4.3. Variação do diâmetro com a pressão ………………………….... 38

4.4. Resistência à pressão ……......................................................... 41

4.5. Perda de carga ....................................................................... 42

4.6. Fator de redução de perda de carga $(\mathrm{F})$....................................... 46

4.7. Dimensionamento das linhas laterais pelo método estatístico ...... 48

5. CONCLUSÕES ……................................................................ 50

6. REFERÊNCIAS BIBLIOGRÁFICAS …..................................... 51 


\section{LISTA DE FIGURAS}

Figura Página

1 Esquema do Tubo gotejador Rain-Tape ....................................... 22

2 Esquema da bancada de testes para os ensaios de uniformidade de

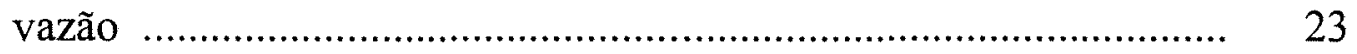

3 Detalhe da tomada de pressão ……............................................ 26

4 Final da linha-teste mostrando a tomada de pressão e o registro .... 26

5 Fluxograma para a determinação do fator de redução de perda de

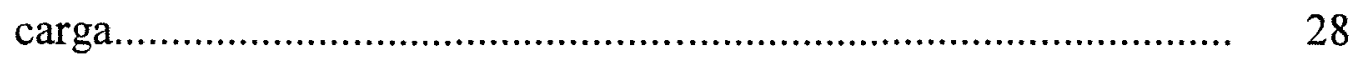

6 Fluxograma para o dimensionamento de linhas laterais pelo método estatístico ...................................................................... 33

7 Curva característica do Tubo gotejador Rain-Tape ...................... 37

8 Curva característica fornecida pelo fabricante ................................ 38

9 Diâmetro da tubulação em função da pressão de operação ............ 40

10 Sequência do processo de ruptura do Tubo gotejador Rain-Tape .. 42 


\section{LISTA DE TABELAS}

Tabela

Página

1 Classificação da uniformidade de vazão

2 Classificação da uniformidade de vazão segundo Abréu et al. (1987)

3 Valores dos coeficientes de variação de fabricação do Tubo gotejador Rain-Tape

4 Vazões fornecidas pelo fabricante e a diferença com as vazões obtidas pela equação ajustada

5 Valores de diâmetro em função da pressão, para o Tubo gotejador Rain-Tape

6 Resultado da análise de variância para comparação entre médias

7 Pressões e locais de ruptura do Tubo gotejador Rain-Tape .........

8 Valores de soma dos quadrados e grau de liberdade do resíduo da análise de variância, para determinação de $\mathrm{Fz}$

9 Fator de redução de perda de carga (F) para o Tubo gotejador Rain-Tape, com espaçamento entre emissores de 0,30 m, em função do número de saídas $(\mathrm{N})$

10 Comprimentos máximos da linha lateral para o Tubo gotejador Rain-Tape 


\section{LISTA DE SÍMBOLOS}

a

$\beta$

C

CVf

$\mathrm{CVH}$

$\mathrm{CVHc}$

CVHp

CVk

$\mathrm{CVq}$

- coeficiente de variação de vazão

Cvqproc. - coeficiente de variação de vazão procurado

D - diâmetro interno da linha lateral (m)

$\Delta \mathrm{T} \quad$ - variação de temperatura

$\Delta Z \quad$ - desnível total $(\mathrm{m})$

deltaz - desnível total $(\mathrm{m})$

Di - diâmetro interno do tubo gotejador ( $\mathrm{mm}$ )

f - fator de atrito da equação universal

F - fator de redução de perda de carga para múltiplas saídas

Gli - grau de liberdade do resíduo das equações comparadas com a equação geral 


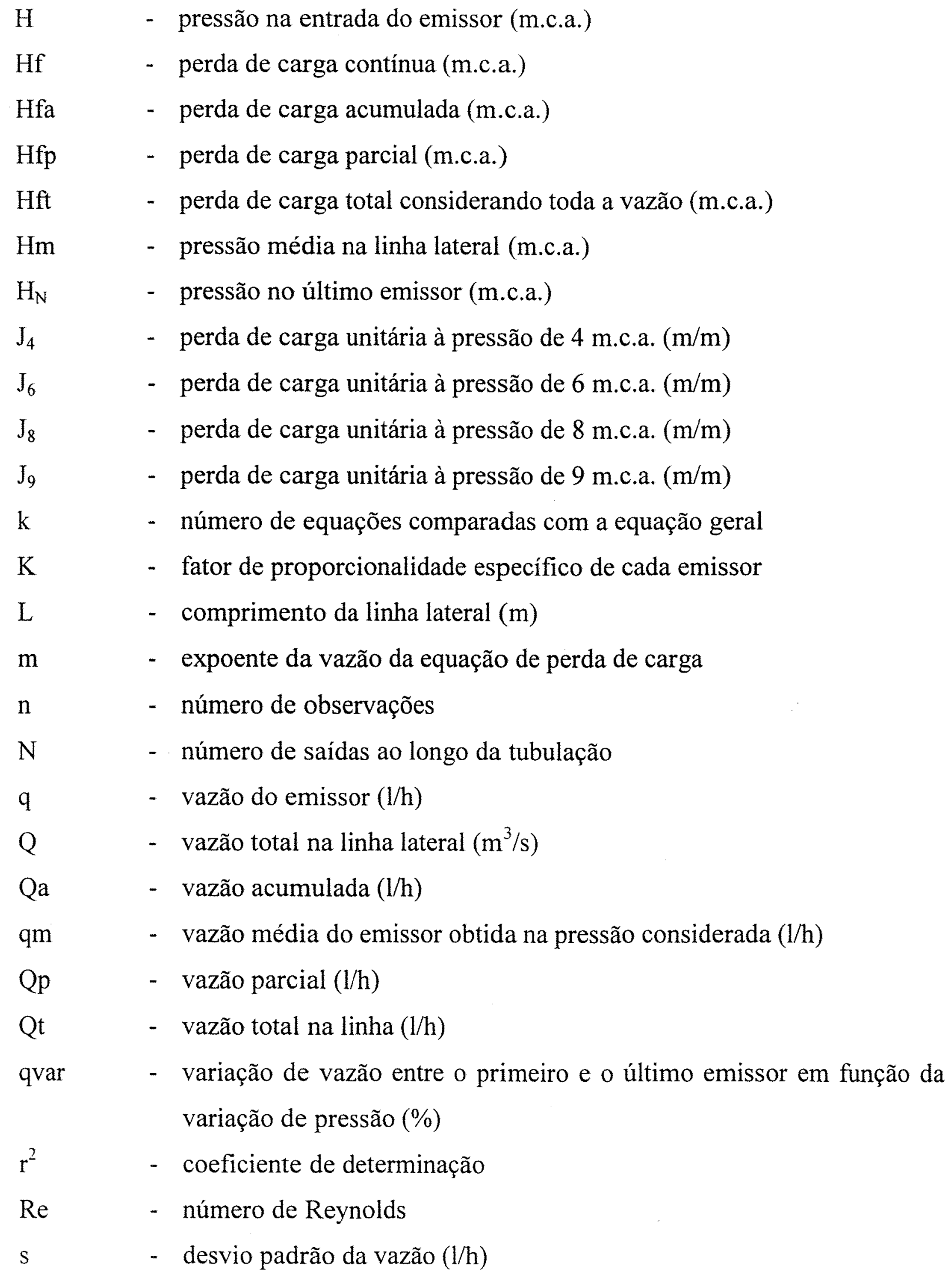


- espaçamento entre emissores (m)

So - inclinação considerada da linha lateral $(\mathrm{m} / \mathrm{m})$

SQi - soma dos quadrados dos desvios das equações comparadas com a equação geral

Sqrg - soma dos quadrados dos desvios da equação geral

teste $F_{Z} \quad$ - teste $F$ proposto por Zar (1974), para comparação de regressões

teste $\mathrm{F} \quad$ - teste usado para análise de variância

VH - variância da pressão

$\mathrm{x}$ - constante que caracteriza o regime de fluxo do emissor. 


\title{
CARACTERIZAÇÃO HIDRÁULICA DE UM TUBO GOTEJADOR
}

\author{
Autor : ANGELITA TERESINHA VIEIRA \\ Orientador : PROF. DR. JOSÉ ANTÔNIO FRIZZONE
}

\section{RESUMO}

Os sistemas de irrigação localizada cada vez mais voltam-se a um mercado exigente, que requer menor custo de implantação e facilidade de operação. Os tubogotejadores surgiram com o intuito de manter as características de qualidade e condições adequadas de funcionamento.

No laboratório de irrigação do Departamento de Engenharia Rural da Escola Superior de Agricultura "Luiz de Queiroz", Universidade de São Paulo, estudou-se as características hidráulicas do tubo gotejador Rain-Tape TPC da Rain-Bird.

Este tubo gotejador é constituído de polietileno linear de baixa densidade com espessura de parede de 225 microns ${ }^{*}$. Os emissores são do tipo labirinto, com fluxo turbulento e espaçados de $0,30 \mathrm{~m}$.

O tubo gotejador foi submetido a diferentes ensaios para a determinação das características hidráulicas : coeficiente de variação de fabricação (CVf), equação característica, variação do diâmetro com a pressão, resistência à ruptura, equação de

\footnotetext{
* 1 micron $-10^{-6} \mathrm{~m}$.
} 
perda de carga, fator de redução de perda de carga (F) e comprimento máximo das linhas laterais.

O ensaio para a determinação da uniformidade de vazão e equação característica, forneceu um Cvf de 1,97\% e constante que caracteriza o regime de fluxo de 0,4563 , respectivamente. Isto classifica os emissores com uniformidade de vazão excelente e regime de fluxo turbulento, concordando com os valores fornecidos pelo fabricante.

A ruptura do material ocorreu à pressão de 21 m.c.a. em locais distintos ao longo do tubo gotejador, nunca nos emissores. A água permaneceu gotejando durante todo o processo de ruptura.

Verificou-se que o diâmetro interno aumenta com o aumento da pressão, tendo sido ajustadas equações de perda de carga considerando a vazão e o diâmetro, e a vazão e a pressão como variáveis. A análise de variância demonstrou não haver diferença entre os valores de perda de carga obtidos pelas equações ajustadas, pela equação universal e os dados experimentais.

Os valores dos coeficientes de redução de perda de carga $(\mathrm{F})$ determinados utilizando-se a equação característica do emissor e a equação de perda de carga (vazão e pressão como variáveis), em função do número de saídas e da pressão, decresceram com o aumento da pressão para um mesmo número de emissores.

Os comprimentos máximos obtidos pelo método estatístico, variaram de 9,0 a 203,1 m. O menor comprimento corresponde a uma pressão de entrada na linha de 2 m.c.a., $3 \%$ de declive e $10 \%$ de qvar e o maior à pressão de 10 m.c.a., $3 \%$ de declive e $20 \%$ de quar. 


\title{
HYDRAULIC CHARACTERISTICS OF DRIP TAPE
}

\author{
Author: ANGELITA TERESINHA VIEIRA \\ Adviser : PROF. DR. JOSÉ ANTÔNIO FRIZZONE
}

\section{SUMMARY}

This work was developed at the Department of Rural Engineering ESALQ/USP. It was studied the hydraulic characteristics of Rain Bird drip tape.

This drip tape is a flexible emitter with long path, with turbulent flow and spacing $0,30 \mathrm{~m}$.

It was used different tests in order to determine the hydraulics characteristics : manufacturing coefficient (Cvf), characteristic equation, diameter variation with pressure, rupture resistance, head loss equation, head loss factor $(\mathrm{F})$ and maximum length laterals.

The test for discharge determination and characteristic equation, was $\mathrm{Cvf}=$ $1,97 \%$ and emitter discharge exponent was 0,4563 . This value agree with the manufacturer.

The internal diameter increased with pressure and the equation were adjusted as a function of discharge and pressure.

The rupture resistance failed at 21 m.c.a. and happened along the drip tape and never in the emitters. 
The variance analysis did not show any significant difference values among the head loss obtained by the adjusted equations, by the universal equation and experimental data.

The head loss factor $(\mathrm{F})$ was obtained using the characteristic equation of the emitter and the head loss equation, were set according to the number of outlets and pressure. $F$ values decrease with the pressure increasing at the same number of emitters.

The maximum length obtained by statistical approach varied from 9,0 to $203,1 \mathrm{~m}$. The smaller length correspond to the pressure of 2 m.c.a., slope $3 \%$ and qvar of $10 \%$, the greater length to the pressure of 10 m.c.a., slope $3 \%$ and quar of $20 \%$. 


\section{INTRODUÇÃO}

Os sistemas de irrigação localizada são projetados e manejados para fornecer uma quantidade frequente de água que mantenha o solo com umidade adequada, objetivando a produtividade em níveis economicamente viáveis. Além disso, é uma das opções de agricultura em regiões onde a exploração agrícola tornou-se inviável pela escassez de água, pois muitas destas regiões apresentam grande potencial para cultivos agrícolas.

Atualmente, existe grande diversificação de sistemas de irrigação localizada, sendo que, o mesmo apresenta grande espectro de aplicação, o que permite as mais variadas adaptações às condições de operação. No Brasil, apesar de os sistemas de irrigação localizada atingirem grande parte das culturas, seu uso é mais restrito às culturas perenes, sendo crescente em cultivo protegido.

A escassez de recursos com o decorrer dos anos cresce cada vez mais, o que gera uma necessidade de reduzir os gastos com energia, ou seja, utilizar sistemas de irrigação com alta eficiência e baixo custo aliados a um reduzido consumo energético.

Maia (1994) acrescenta que o método de irrigação localizada, geralmente é o que requer o maior investimento inicial, por possuir toda a rede hidráulica fixa, mas tem o menor custo operacional quando comparado com os demais métodos.

Devido a exigência do mercado e a necessidade de redução nos custos de implantação de sistemas de irrigação localizada, além de melhor facilidade de manuseio, surgiu no mercado sistemas de gotejamento confeccionados com material flexível, os tubo gotejadores.

Os tubo gotejadores são emissores inseridos na própria tubulação de

polietileno na forma de labirintos. Devido ao tipo de material, diâmetro, espessura e 
o processo de inserção do emissor, seu custo é extremamente reduzido, além de seu fácil transporte e instalação.

Objetivando um correto dimensionamento hidráulico dos sistemas de irrigação localizada é necessário conhecer suas características hidráulicas. No caso dos tubo gotejadores, que são relativamente novos no mercado nacional, conhecer suas características de funcionamento torna-se essencial.

Portanto, este trabalho objetiva determinar as caracteristicas hidráulicas para o tubo gotejador Rain-Tape TPC, da Rain-Bird ou seja :

- uniformidade de vazão;

- equação característica do emissor;

- variação do diâmetro interno com a pressão;

- resistência do material à pressão e local de ruptura;

- equação de perda de carga;

- fator de redução de perda de carga (F); e

- comprimento máximo de linhas laterais. 


\section{REVISÃO DE LITERATURA}

A irrigação localizada é um método em que a água é aplicada ao solo em pequenas quantidades, porém, com alta frequência, diretamente sobre a região radicular, de modo a manter o teor de água do solo, próximo à capacidade de campo.

Os sistemas de irrigação localizada aproveitam o máximo dos recursos hídricos disponíveis, permitindo a irrigação das culturas, mesmo com a utilização de mananciais insuficientes para os demais métodos de irrigação (Schmidt, 1995).

Para Maia (1994), a irrigação localizada foi inicialmente adotada em culturas altamente produtivas e em pomares, situados em regiões onde a água era escassa e de elevado custo. Atualmente, tal sistema é utilizado em várias culturas e, também, em áreas onde o recurso água não é fator limitante.

Nakayama \& Bucks (1986) citam que as principais vantagens dos sistemas de irrigação localizada são :

- maior eficiência do uso da água;

- possibilidade de obtenção de uma maior produtividade;

- pode ser utilizado com água salina ou em solos salinos;

- maior eficiência na aplicação de fertilizantes;

- limita o crescimento de plantas daninhas;

- pequena necessidade de mão-de-obra;

- não interfere nas práticas culturais;

- menor requerimento de energia em relação a outros sistemas pressurizados de irrigação.

As principais limitações, por sua vez são :

- possibilidade de obstrução total ou parcial dos emissores; 
- o sistema radicular concentra-se no volume de solo úmido, ocasionando em alguns casos, uma diminuição da estabilidade das plantas;

- acúmulo de sais na periferia do bulbo molhado;

- elevado custo inicial.

Com a crescente poluição e escassez dos recursos hídricos, o método de irrigação por gotejamento é uma solução, pois é necessário aproveitar ao máximo os recursos hídricos disponíveis, permitindo a irrigação das culturas mesmo com a utilização de mananciais insuficientes para os demais métodos de irrigação (Vieira, 1975).

Segundo Bernardo (1989), a introdução do método de irrigação por gotejamento não deve ser considerada somente como uma nova técnica para suprir água às culturas, mas sim, como uma nova filosofia em termos de aplicação de água, fazendo parte integrante de um conjunto de técnicas agrícolas nos cultivos de determinadas plantas, sob condições controladas de umidade do solo, adubação, salinidade, fitossanidade e variedades selecionadas, de modo que se obtenham efeitos significativos na produção por área e por água consumida, bem como na época da colheita e na qualidade do produto.

Para Maia (1994), os emissores são os elementos de maior importância nas instalações de irrigação localizada. São dispositivos que possibilitam a distribuição de um fluxo de água com vazão e frequência constantes. $\mathrm{O}$ fluxo de água nos emissores, conectados nas tubulações, sofre uma dissipação de energia tal, que resulta em gotas ou pequenos jatos, que são fornecidos a um ponto ou a uma área do solo.

O gotejamento caracteriza-se pela liberação de água para o solo de modo puntual, através de dispositivos denominados gotejadores, na forma de gotas e em vazões reduzidas. Este tipo de irrigação pressupõe um sistema de filtragem de água adequado, considerando que a água de irrigação poderá conter fertilizantes e outros produtos químicos. 
Qs gotejadores, segundo Abréu et al (1987), são emissores com vazões inferiores a $201 / h^{1}$ que para serem selecionados, devem apresentar as seguintes características :

- vazão constante e uniforme;

- pouca sensibilidade a variações de pressão e a entupimentos;

- alta uniformidade de fabricação;

- resistente a produtos químicos, ambientais e a operações agrícolas;

- baixo custo;

- estabilidade na relação vazão-pressão ao longo do tempo;

- pouca sensibilidade a variações de temperatura e;

- reduzida perda de carga nas conexões.

Quanto a sua inserção na linha lateral os emissores podem estar conectados na linha, sobre a linha ou através de sistema integrado onde o emissor já vem embutido na linha lateral.

Para Schmidt (1995), com relação ao princípio de funcionamento, os gotejadores podem ser classificados em :

- gotejadores de longo percurso de saída (microtubo, labirinto, etc.);

- gotejadores com orifício de saída (orifícios simples, saída dupla, membrana com orifícios);

- gotejadores com câmara de vórtice (câmara simples, câmara múltipla).

Segundo Bernardo (1989), a vazão dos gotejadores, em geral, varia entre 1 e $10 \mathrm{l} / \mathrm{h}$. Normalmente, eles trabalham sob uma pressão de 10 m.c.a. ${ }^{\mathcal{D}}$, podendo variar de 5 a 30 m.c.a. Existem emissores que apresentam vazão constante numa ampla faixa de pressão.

Como o dimensionamento da linha lateral é função da variação de vazão entre o primeiro e o último emissor na linha lateral, variação esta que geralmente está

\footnotetext{
${ }^{1} 1 \mathrm{~m}^{3} / \mathrm{s}-3,6 \times 10^{6} \mathrm{l} / \mathrm{h}$

${ }^{2} 1$ m.c.a. $-9.807 \mathrm{kPa}-0,0966 \mathrm{~atm}$.
} 
limitada em 10 a $20 \%$ da vazão média dos gotejadores ao longo da lateral, os gotejadores de vazão constante, permitem dimensionar sistemas com linhas laterais mais longas, o que diminui o custo do sistema.

Vários fabricantes têm projetado gotejadores para reduzir variações de vazão causadas pelas mudanças de pressão, Moraes (1985) cita alguns deles :

- gotejadores auto-reguláveis;

- laterais de tubos de parede dupla;

- gotejadores de alta perda de carga (labirintos).

Mayers \& Bucks (1972) citam que os sistemas de irrigação por gotejo que trabalham com pressões mais elevadas, onde no gotejador ocorre alta perda de carga, tem oferecido a melhor oportunidade para a uniformidade de vazão dos gotejadores. Previamente projetados, os sistemas de baixa pressão tem suportado a desuniformidade de vazão dos emissores devido as mudanças de pressão induzidas por atrito ao longo da linha lateral, representando uma alta porcentagem da pressão total.

Segundo Keller \& Karmeli (1975), o custo de implantação de um sistema de irrigação por gotejamento é alto, enquanto os custos de operação e manutenção são baixos, em relação a outros sistemas fixos. Os gotejadores contribuem com 25 a $30 \%$ do custo inicial.

Visando à redução de custos e facilidade de instalação no campo, atualmente tem-se usado tubos e mangueiras de polietileno de baixa densidade, alguns deles perfurados a laser, outros manualmente e outros onde o emissor é fabricado e inserido na própria tubulação da linha lateral, como é o caso dos tubo gotejadores com labirinto.

Abréu et al. (1987) classificam o gotejador tipo labirinto como um sistema integrado, onde os emissores são inseridos no interior da linha no próprio processo de fabricação, uniformemente espaçados e apresentam vazões inferiores a $4 \mathrm{l} / \mathrm{h}$. Dependendo da vazão, da tolerância a pressão e do diâmetro da tubulação, as laterais 
apresentam comprimentos variáveis, que em casos mais favoráveis, podem chegar a $300 \mathrm{~m}$.

Os mesmos autores acrescentam que os sistemas integrados são muito semelhantes as mangueiras de gotejamento (do tipo "Twin-wall" - parede dupla), e distinam-se a reduzir custos nos cultivos onde se requer grande quantidade de gotejadores. A vida útil é função da qualidade do material, em geral devem durar no mínimo duas safras. O diâmetro é geralmente inferior a $25 \mathrm{~mm}$, e o espaçamento entre emissores varia de acordo com as necessidades relacionadas a cada cultura (os mais usuais estão entre 0,30 a $1,50 \mathrm{~m}$ ). A pressão mínima de trabalho está na ordem de 0,3 a 0,5 atm e a máxima entre 3 e 4 atm.

No dimensionamento de sistemas de irrigação localizada, deve-se considerar a variabilidade existente de gotejador para gotejador, decorrentes do processo de fabricação. Considerando que as secções transversais de fluxo são normalmente de diâmetros reduzidos, a fabricação deverá ser exata e bastante uniforme, pois pequenas variações poderão causar grandes diferenças na vazão.

Portanto, dois gotejadores retirados de um mesmo lote, testados a pressão e temperatura constantes, poderão ter diferentes vazões. Esta diferença variará de um modelo para outro, dependendo do projeto do gotejador, dos materiais usados em sua construção e do controle de qualidade com o qual é fabricado.

De acordo com Bralts et al. (1981) o fator de proporcionalidade da equação de fluxo do emissor $(\mathrm{K})$, inclui no seu valor os fatores relacionados com a fabricação do emissor, como por exemplo, o coeficiente de descarga e a área da secção transversal dos emissores tipo orifício. Portanto, quando se considera as variações de vazão do emissor devido à fabricação, deve sempre se referir ao valor de $\mathrm{K}$.

Solomon (1979) diz que devido ao fato dos emissores usados em irrigação localizada possuírem dimensões muito reduzidas, dificulta a sua construção precisa, fazendo com que a variação de vazão em função da variação na construção dos emissores não possa ser ignorada. 
Botrel (1984) acrescenta que pequenas variações nestes orifícios de saída de água (1 a $2 \mathrm{~mm}$ ), provocam grandes diferenças na vazão a uma mesma pressão. Vermeiren \& Jobling (1980) afirmam que estas diferenças podem ultrapassar a 10\%, o que em alguns casos as tornam mais importantes que as variações de vazão devidas a diferenças de pressão ao longo da linha lateral.

Keller \& Karmeli (1974) comentam sobre a uniformidade dos sistemas de irrigação por gotejamento, e citam que esta uniformidade depende também da precisão com que os emissores são fabricados.

Solomon (1979) fez diversas considerações que fornecem uma justificativa supondo que as vazões dos emissores, em uma dada pressão, são normalmente distribuídas, em função do processo de fabricação.

Assumindo que as diferentes vazões ocasionadas pelos processos construtivos têm distribuição normal, isto permite utilizar os conceitos de estatística correspondentes a essa distribuição para conclusões quantitativas.

Solomon (1979) determinou então a variação da fabricação de vários emissores tipo-orifício, classificou e deu uma interpretação física para o coeficiente de variação de fabricação. Segundo o autor, a totalidade das observações de vazão está compreendida no interválo $(1 \pm 3 \mathrm{CVf}) . q \mathrm{~m}$; aproximadamente $95 \%$ das observações estão compreendidas no interválo $(1 \pm 2 \mathrm{CVf}) . q \mathrm{qm}$ e $68 \%$ das observações, estão compreendidas no interválo $(1 \pm C V f) . q m$; em que qm é a vazão média e CVf o coeficiente da variação de fabricação.

O mesmo autor propôs, então, um coeficiente de variação de fabricação, dado pela expressão :

$$
\mathrm{CVf}=\frac{\mathrm{s}}{\mathrm{qm}}
$$

em que : 
CVf - coeficiente da variação de fabricação (\%);

s - desvio padrão da vazão $(1 / h)$;

qm - vazão média de uma amostra adequada de emissores testados a uma pressão normal de operação $(\mathrm{l} / \mathrm{h})$.

Segundo o autor, o CVf é um importante fator que influencia a uniformidade de emissão da água, e portanto, a eficiência do sistema de irrigação. Recomenda o CVf como medida numérica apropriada da consistência de unidade para unidade de gotejadores e cujos valores típicos oscilam entre 0,02 e 0,10 , podendo algumas vezes serem observados valores mais elevados.

Torna-se importante, portanto, quando se seleciona um emissor, conhecer o CVf que deve ser fornecido pelo fabricante.

Existem diversas classificações de emissores quanto a uniformidade de vazão (Solomon, 1979; Soil Conservation Service - USDA, 1979; ABNT, 1986), Tabela 1.

Tabela1 - Classificações da uniformidade de vazão.

\begin{tabular}{cc}
\hline Cvf $(\%)$ & Classificação da uniformidade \\
\hline & Solomon (1979) \\
\hline até 3 & excelente \\
4 a 7 & média \\
8 a 10 & marginal \\
11 a 14 & pobre \\
acima de 15 & ruim \\
\hline Soil Coservation Service - USDA (1979) \\
\hline até 3 & excelente \\
4 a 7 & média \\
7 a 11 & marginal \\
11 a 15 & pobre \\
acima de 15 & inaceitável \\
\hline \multicolumn{1}{c}{ ABNT (1986) - PNB 12:02.08-022 } \\
\hline até 10 & boa \\
10 a 20 & média \\
20 a 30 & marginal \\
acima de 30 & inaceitável \\
\hline
\end{tabular}


A classificação mais recente é a apresentada por Abréu et al (1987) na tabela 2, em que os emissores são separados em dois grupos e classificados.

Tabela 2 - Classificação da uniformidade de vazão segundo Abréu et al.(1987)

\begin{tabular}{cc}
\hline Cvf $(\%)$ & Classificação da uniformidade \\
\hline Grupo 1 - Gotejadores, miniaspersores e difusores \\
\hline até 5 & bons \\
5 a 10 & médios \\
10 a 15 & deficientes \\
acima de 15 & inaceitáveis \\
\hline Grupo 2 - Tubo gotejadores ou mangueiras de gotejamento \\
\hline até 10 & bons \\
10 a 20 & médios \\
acima de 20 & deficientes e inaceitáveis \\
\hline
\end{tabular}

Testezlaf \& Campioni (1993) encontraram para o tubo gotejador "Queen Gil", com sistema de emissores tipo labirinto, espaçados de $30 \mathrm{~cm}$, CVf médio de $2,8 \%$ indicando uma boa qualidade de fabricação. Schmidt (1995), estudando também o comportamento do tubo gotejador "Queen Gil", para a pressão de $66,7 \mathrm{kPa}$ e temperatura média igual a $30^{\circ} \mathrm{C}$, a vazão média dos emissores foi de $1,331 / \mathrm{h}$, com um CVf de $3,11 \%$.

Para a determinação experimental do CVf e da relação vazão versus pressão, a ABNT (1986) estabelece que seja estudada uma amostra de no mínimo 50 unidades para gotejadores e 20 para microaspersores, obtidas aleatoriamente na linha de produção da fabricante.

A relação entre vazão e pressão, a perda de carga ao longo da linha lateral e no gotejador e o percurso da água no gotejador, constituem as características hidráulicas que influenciam, diretamente, o desempenho do sistema. Essas características são influenciadas pelo tipo de gotejador, material, processo de fabricação e método de conexão do gotejador na linha (Gillard et al., 1974). 
Soares (1978) propõe que estas características sejam determinadas em laboratório e devem estar sempre disponíveis aos projetistas e usuários deste método de irrigação.

Segundo Keller \& Karmeli (1975), a equação que descreve a vazão nos emissores pode ser apresentada como segue :

$$
q=K \cdot H^{x}
$$

em que :

q - vazão do emissor $(1 / \mathrm{h})$;

$\mathrm{K}$ - coeficiente específico de cada emissor;

H - Pressão na entrada do emissor (m.c.a.);

$\mathrm{x}$ - Constante que caracteriza o regime de escoamento.

Os autores comentam que a redução na vazão é menos influenciada pela variação de pressão, à medida que o valor de " $x$ " decresce. Os valores de " $x$ " relacionam-se com o regime de escoamento, para regime turbulento $\mathrm{x}=0,5$ e regime laminar $\mathrm{x}=1,0$. Para orifícios perfeitamente autocompensantes $\mathrm{x}=0$ e para gotejadores de longo percurso " $x$ "pode variar de 0,5 a 1,0 .

Schmidt (1995) estudando o tubo gotejador "Queen Gil", encontrou um expoente da pressão igual a 0,6616 e caracterizou o regime de escoamento como turbulento.

Testezlaf \& Campioni (1993), avaliando o tubo gotejador "Queen Gil", encontraram um expoente de 0,625. Concluíram que o valor deste coeficiente demonstra que o regime de escoamento do gotejador ou está dentro da região de transição, ou está próximo da região laminar. Este valor também evidencia que o sistema é sensível à variação de pressão. 
Segundo Abréu et al. (1987), por mais precisos que sejam os processos de fabricação dos emissores ocorrem diferenças na fabricação,refletindo assim nos valores dos coeficientes da equação de fluxo do emissor (K e X).

Além do processo de fabricação e da variação de pressão ao longo da linha lateral, a variação de temperatura da água também contribui para que haja variações na vazão dos gotejadores. Segundo Parchomchuk (1976), mudanças na viscosidade, em função da temperatura da água, podem causar variações na vazão dos emissores maiores do que o limite máximo, de $\pm 10 \%$, caso o regime de escoamento no emissor seja laminar. Quando o regime de escoamento no emissor for turbulento, a vazão não será afetada por mudanças na viscosidade.

Segundo Faria (1981), uma variação de $25^{\circ} \mathrm{C}$ ( 20 para $45^{\circ} \mathrm{C}$ ) na temperatura da água acarreta uma variação na vazão do microgotejador IRTEC (gotejador tipo orifício) de $1,24 \%$.

Keller \& Karmeli (1975), estudando o efeito da temperatura da água na vazão de gotejadores, observaram que em se tratando de fluxo turbulento esta influência é pequena, porém, quando o regime de fluxo é laminar e instável, a vazão varia diretamente com a viscosidade da água.

Silva (1984), fazendo variar a temperatura da água descarregada por orifícios, ao longo da linha lateral, entre 25 e $45^{\circ} \mathrm{C}$, verificou que a temperatura da água não provocou grandes variações na vazão dos orifícios. Para os orifícios com $0,61 \mathrm{~mm}$ e $1,08 \mathrm{~mm}$ de diâmetro a amplitude de variação de vazão foi de 1,4\% e 2,5\%, respectivamente.

Peng et al (1986) derivaram diversas equações teóricas para descrever o efeito das mudanças de temperatura sobre o comportamento hidráulico das linhas laterais da irrigação por gotejamento. Quando o tamanho do tubo e a vazão total são considerados constantes, o efeito da temperatura sobre o atrito total até o final da linha, pode atingir até $10 \%$ baseado em uma situação extrema na faixa de $-50^{\circ} \mathrm{C}$ a 
$+50^{\circ} \mathrm{C}$ comparando com a condição básica de $20^{\circ} \mathrm{C}$ e $\Delta \mathrm{T}=0$. O efeito da temperatura sobre o gradiente de energia foi insignificante, e uma diferença de temperatura na faixa de 20 a $50^{\circ} \mathrm{C}$ ao longo da linha, pode causar apenas 1 a $2 \%$ de diferença em relação a perda de carga.

Segundo Lencastre (1983), numa mangueira, a resistência ao movimento do fluido é função não só da rugosidade mas também da pressão absoluta pois, para maiores pressões, devido à elasticidade do material, o diâmetro aumentará.

Andrade (1990), determinando as características hidráulicas de tubos flexíveis de polietileno perfurados a laser, verificou que com o aumento da pressão ocorre um aumento no diâmetro interno do tubo e estabeleceu uma relação potencial de acordo com as pressões de 1 a 10 m.c.a.

Schmidt (1995) determinou para o tubo gotejador "Queen Gil" o raio hidráulico entre as pressões de 20,1 e $110,2 \mathrm{kPa}$, ajustando uma equação potencial relacionando o diâmetro com a pressão. Concluiu que a variação do diâmetro nesta faixa de pressão foi inferior a $1 \%$ e, portanto, o efeito do dimensionamento pode ser considerado constante.

$\mathrm{O}$ aumento do diâmetro ocorre até uma certa pressão, a partir da qual a integridade da parede do tubo flexível fica comprometida, podendo romper-se.

Testezlaf \& Campioni (1993) determinaram as pressões de ruptura para o tubo gotejador "Queen Gil". Usaram diferentes comprimentos de tubo gotejador com o objetivo de verificar se o número de gotejadores presentes na linha afetava significativamente o momento da ruptura. Encontraram uma pressão média de ruptura de $3,9 \mathrm{kgf} / \mathrm{cm}^{2}$ Aplicando o teste $\mathrm{F}$, verificaram que o número de gotejadores na linha não afetou significativamente a pressão de ruptura.

Em geral, a vazão através de um gotejador é controlada pela carga hidráulica na entrada do gotejador e pelo caminho percorrido pela água dentro do gotejador. Se a geometria do emissor for fixada, verificar-se-á, então, ao longo da linha lateral, 
uma variação de vazão do emissor, correspondente à variação na pressão ao longo da linha lateral. Uma uniformidade de vazão para os emissores poderá ser possível coma a mudança do tipo do emissor. Entretanto, na prática, as características dos emissores, geralmente, são fixadas e a variação de vazão é determinada apenas pela variação de pressão (Howell \& Hiller,1974).

Várias equações permitem calcular a perda de carga contínua numa linha lateral, dentre elas a equação de Hazen-Willians, Darcy-Weisbach (universal) e a fórmula de Cruciani-Margazitória, utilizada para tubulações de polietileno de pequenos diâmetros (Andrade, 1990).

Segundo Bezdek \& Solomon (1978), estudos feitos por Urbina ${ }^{3}$ (1977) e Paraqueima ${ }^{4}$ (1977) mostram que, apesar de se selecionar o valor de C para uso da equação de Hazen-Willians, a equação de Darcy-Weisbach é mais precisa para calcular as perdas de carga em tubos de plástico com pequeno diâmetro.

A equação de Darcy-Weisbach pode ser utilizada tanto em regime laminar como em regime turbulento com resultados satisfatórios. $O$ fator de atrito dessa equação depende do número de Reynolds e da rugosidade relativa do tubo. Como em irrigação por gotejamento são usados tubos lisos (polietileno prensado, PVC flexível etc.), a rugosidade relativa pode ser desprezada, considerando-se apenas o número de Reynolds. O fator de atrito f pode ser obtido pelas seguintes expressões:

- Para regime laminar $(\operatorname{Re}<2.000)$ :

$$
\mathrm{f}=\frac{64}{\mathrm{Re}}
$$

\footnotetext{
${ }^{3}$ URBINA. J. Head loss characteristics of trickle irrigation hose with emitters. Logan, 1977. 54p. (MS)-Utah State University.

${ }^{4}$ PARAQUEIMA, J. Study of some frictional characteristics of small diameter tubing for trickle irrigation lateral. Logan, 1977. 64p. (MS)-Utah State University.
} 
- Para regime turbulento ( $\mathrm{Re} \leq 100.000)$, f é corretamente representado pela fórmula de Blasius :

$$
f=0,316 \cdot \operatorname{Re}^{-0,25}
$$

em que :

f - fator de atrito da fórmula de Darcy-Weisbach;

Re - número de reynolds.

Assy (1977) afirma que a fórmula de Hazen-Willians é correta apenas para condutos hidraulicamente lisos e para o número de Reynolds acima de 500.000. Em tais circunstâncias, o valor de $\mathrm{C}$ é constante e igual a 158. Nos demais casos, o valor de C é uma função do número de Reynolds e da rugosidade relativa.

No entanto, Howell \& Barinas (1980) usando tubos de PVC e polietileno de $25 \mathrm{~mm}$ de diâmetro e água a $24^{\circ} \mathrm{C}$, compararam as perdas de carga nestes tubos quando calculadas pela equação de Darcy-Weisbach ( usando a equação de Blasius para estimar o fator de atrito) e pela equação de Hazen-Willians ( $C=150$ ). Verificaram que para vazões até $3.500 \mathrm{l} / \mathrm{h}$, não houve diferença significativa entre elas, sendo que, este ponto corresponde a um número de Reynolds superior a 50.000 .

Segundo Bezdec \& Solomon (1978), a equação de Hazen-Willians não é aconselhável para calcular as perdas de carga em tubos de pequeno diâmetro e baixa velocidade, nem para baixos valores de número de Reynolds. Essa equação não considera a viscosidade do fluido e está baseada em dados obtidos com altos valores de número de Reynolds.

Wu e Gitlin (1973) afirmam que o uso da equação de Blasius para determinar o fator de atrito, pode ser objeto de alguns erros, causados por :

- condição de regime de escoamento laminar desenvolvidas em certas secções ao longo do tubo, e

- certos tipos de emissores inseridos no tubo, criando maior atrito. 
Para reduzir estes tipos de erros são necessários experimentos em laboratório, que determinem a melhor relação entre o fator de atrito e o número de Reynolds, para diferentes tipos de linhas de irrigação por gotejamento.

As diferentes fórmulas apresentadas para o cálculo da perda de carga contínua em tubulações virgens e em condições de escoamento em regime permanente, podem ser agrupadas, segundo Silvestre ${ }^{5}$ (1979) citado por Schmidt (1995), em uma única fórmula :

$$
\mathrm{Hf}=\beta \cdot \mathrm{Q}^{\mathrm{m}} \cdot \mathrm{L}
$$

em que :

Hf - perda de carga contínua (m.c.a.);

$\beta$ - parâmetro que depende da fórmula utilizada, do diâmetro interno da tubulação, do material empregado na fabricação da tubulação e do estado de conservação desta; Q - vazão nominal $(\mathrm{m} / \mathrm{s})$;

L - comprimento da tubulação (m);

m - expoente da vazão.

Um importante passo no dimensionamento de um sistema de irrigação por gotejamento é determinar a perda de carga na linha lateral de irrigação. $O$ comprimento, o diâmetro, a declividade da linha lateral, o espaçamento entre emissores e a vazão dos mesmos devem ser considerados (Silva, 1984). Além disso, Howell \& Barinas (1980) citam vários autores que recomendam considerar a perda de carga localizada em virtude da inserção dos emissores na linha lateral.

Oliveira (1978) e Soares (1981), trabalhando com microtubos, separaram as perdas de carga contínuas das perdas de carga localizadas e verificaram, que o valor

${ }^{5}$ SILVESTRE, P. Hidráulica Geral. 2ed. Rio de Janeiro : Livros Técnicos e Científicos, 1982. 316p. 
do coeficiente de perda de carga localizada diminui com o aumento do número de Reynolds.

Silva (1984), estudando as características hidráulicas de tubos de polietileno de diâmetro nominal igual 3/8", perfurados manualmente, verificou que a perda de carga na linha de teste sem orifícios foi igual a perda de carga na linha de testes com orifícios vedados, verificando não ocorrer perda de carga na inserção do emissor.

$\rightarrow O$ ideal seria que a aplicação de água por todo o sistema de gotejamento fosse absolutamente uniforme. Para gotejadores espaçados uniformemente, isso exigiria que cada gotejador tivesse a mesma vazão, embora diferenças de pressão sejam inevitáveis ao longo da linha lateral.

Segundo Wu \& Gitlin (1974a), a uniformidade de aplicação de água da linha lateral está relacionada com a variação de vazão dos emissores, que é uma função do comprimento da linha e pressão de entrada, do espaçamento entre emissores e da taxa de fluxo total. Para Howell \& Hiller (1974), essa variação também é devida a perdas de carga por atrito ao longo da tubulação e nas inserções dos gotejadores, a ganhos e perdas de energia de posição, a qualidade de matéria-prima e processos de fabricação, a obstruções e efeitos da temperatura da água sobre o regime de escoamento e, a geometria do emissor.

Uma das maneiras de determinação da perda de carga que realmente ocorre no tubo e nos gotejadores é computar a variação de pressão entre duas saídas adjacentes, adicionando-a à que ocorre no ponto de inserção do gotejador. Tal cálculo é feito partindo-se do final para o início da linha lateral.

Christiansen (1942), trabalhando com irrigação por aspersão, propôs um método para simplificar o cálculo de perda de carga em linhas laterais com aspersores espaçados uniformemente. Determinou um fator "F" que, multiplicado pela perda de carga no tubo sem saídas laterais, permite estabelecer a perda de carga na linha lateral de irrigação. Exprimiu o valor de " $F$ " em função do número de 
aspersores "N"(ou saídas) e do expoente "m" da vazão da equação de perda de carga, ou seja

$$
F=\frac{1}{m+1}+\frac{1}{2 N}+\frac{\sqrt{(m+1)}}{6 N^{2}}
$$

em que :

F - coeficiente de Christiansen;

$\mathrm{m}$ - expoente da vazão na fórmula usada para o cálculo da perda de carga;

$\mathrm{N}$ - número de saídas ao longo da tubulação.

Karmeli \& Keller (1974) apresentaram valores de "F" compreendidos entre 1 e 0,356 para um número de gotejadores variando de 1 a 100 . Valores semelhantes também foram sugeridos por Olitta (1984) para a mesma faixa de emissores considerada.

Howell \& Hiller (1974) observaram que os valores de "F" aumentam para um mesmo número de gotejadores, diminuindo-se os espaçamentos entre eles. Concluíram que este coeficiente é mais influenciado pelo atrito no gotejador que pelo espaçamento entre eles, e menos influenciado pela pressão na linha lateral.

Oliveira (1978), Soares (1981), Faria (1981) e Botrel (1984), estudando a hidráulica de linhas laterais para irrigação localizada, observaram que o valor de "F" aumentou para um mesmo número de emissores à medida que diminui o espaçamento entre os mesmos.

Andrade (1990) verificou que para um mesmo espaçamento entre emissores os valores de "F" decrescem quando se aumenta o número de orifícios e, aumentam quando a pressão é incrementada, a partir de um determinado número de emissores. Acrescenta que os valores experimentais encontrados foram mais semelhantes aos 
valores tabelados por Christiansen, para as fórmulas de Flamant, CrucianiMargazitória e Veronese.

O método de Christiansen permite, por meio de métodos iterativos, calcular o máximo comprimento das linhas laterais em função da máxima variação de vazão (qvar), permitida entre o primeiro e o último emissor.

Vários métodos de dimensionamento de linhas laterais foram apresentados por diversos pesquisadores como Braud \& Soom (1981), Howell \& Hiller (1974) e Wu \& Gitlin (1974b), considerando apenas a variação de pressão ao longo da linha lateral.

Howell \& Hiller (1974) e Keller \& Karmeli (1974), incluíram os três principais fatores da variação de vazão dos emissores ao longo da linha lateral de irrigação na forma geral da equação de fluxo do emissor. Estes fatores são o expoente de fluxo do emissor $(\mathrm{x})$, seu fator de proporcionalidade $(\mathrm{K})$ e sua pressão na entrada $(\mathrm{H})$. Acrescentam que o fator de proporcionalidade $(\mathrm{K})$ varia de emissor para emissor devido a fabricação, a pressão $(\mathrm{H})$ varia ao longo da linha lateral devido ao atrito e ao desnível e o expoente (x) é considerado constante para um dado tipo de emissor.

Anyoji \& Wu (1987), desenvolveram uma técnica para o cálculo do comprimento máximo de linhas laterais usando a aproximação estatística. Expressaram as variações de vazão do emissor como o fator de proporcionalidade $(\mathrm{K})$ e a pressão $(\mathrm{H})$, estatísticamente em termos de coeficiente de variação (CVk e CVH, coeficiente de variação de fabricação e coeficiente de variação devido a fatores hidráulicos, respectivamente). Considerando $\mathrm{K} \mathrm{e} \mathrm{H}$ da equação de fluxo do emissor $\mathrm{q}=\mathrm{K} . \mathrm{H}^{\mathrm{x}}$, como duas variáveis ao acaso, uma equação de vazão média dos emissores pode ser derivada usando o Teorema de Taylor. Uma vez que o critério de projeto de variação de vazão do emissor (expresso como coeficiente de variação) é fixo e o tipo de emissor é selecionado, o CVH requerido para a linha lateral pode ser calculado e o seu comprimento determinado. 
Independente das diferenças de vazão ocasionadas pelos fatores construtivos, as vazões não são constantes em todos os emissores, devido às diferentes pressões a que estão submetidos, em função da perda de carga que ocorre nas tubulações e do desnivel geométrico.

Assim, Sammis \& Wu (1985) relatam que numa linha lateral, o coeficiente de variação de vazão dos emissores, resultante apenas dos efeitos hidráulicos (CVH), em geral é da ordem de 3,7 a 7,8\%. Estes valores decorrem de uma variação de vazão em função da variação de pressão $\left(\operatorname{qvar}_{(\mathrm{H})}\right)$ da ordem de 10 a $20 \%$. Relacionaram estes dois parâmetros da seguinte forma :

$$
\mathrm{CVH}=0,353 \cdot \mathrm{q}_{\operatorname{var}(\mathrm{H})}+0,198\left(\mathrm{q}_{\operatorname{var}(\mathrm{H})}\right)^{2}
$$

O dimensionamento de uma linha lateral de um sistema de irrigação localizada, ou seja, a determinação do comprimento e do diâmetro, é função da variação da vazão entre o primeiro e o último emissor ao longo desta (Andrade, $1990)$.

Keller \& Karmeli (1975), Vermeirein \& Jobling (1980) e Pueyo \& Forcada (1982), adotam o critério de dimensionamento de projeto, de se permitir uma variação de vazão máxima de $10 \%$ entre emissores funcionando simultaneamente.

De acordo com o critério adotado por Wu \& Gitlin (1974b), uma variação de vazão aceitável seria de $20 \%$ da vazão nominal, e uma variação desejável seria de $10 \%$ desta vazão.

Segundo Bernardo (1989) quando se trata de irrigação complementar, pode-se admitir o limite máximo de $20 \%$ da vazão de serviço, o que corresponderia a uma perda de carga ao longo da linha lateral de aproximadamente $44 \%$ da pressão de serviço para emissores que operam em regime de escoamento turbulento. 


\section{MATERIAL E MÉTODOS}

O trabalho foi conduzido no Laboratório de Irrigação do Departamento de Engenharia Rural da Escola Superior de Agricultura "Luiz de Queiroz" (ESALQ/USP) em Piracicaba/SP.

Fez-se o estudo do tubo gotejador Rain-Tape TPC, fabricado pela Rain-Bird, constituído de polietileno linear de baixa densidade com espessura de parede de 225 microns.

Os gotejadores são autocompensáveis, do tipo Labirinto, que promove a passagem de água com fluxo turbulento. Na Figura 1 esquematiza-se o tubo gotejador Rain-Tape e a forma de seu gotejador. O tubo gotejador Rain-Tape tem emissores espaçados de $0,30 \mathrm{~m}$.

\subsection{Uniformidade de vazão}

Para a realização dos ensaios para determinar a uniformidade de vazão dos emissores, ou seja, seu Coeficiente de variação de fabricação, retirou-se de um rolo de $1.600 \mathrm{~m}$ de comprimento, amostras (4 segmentos) que continham 52 gotejadores.

Cada segmento possuía 4,20 m de comprimento, totalizando 13 gotejadores úteis que foram testados ao mesmo tempo e submetidos a diferentes pressões de entrada (2 a $10 \mathrm{mca}$ ), em uma bancada de testes. As pressões de entrada foram medidas através de um manômetro de mercúrio, conectado à entrada da linha-teste. No final da linha foi conectada uma válvula com fechamento automatico quando a 
linha pressuriza-se, permitindo assim uma completa saída de todo o ar do sistema. Utilizou-se um filtro de 200 mesh conforme o recomendado pelo fabricante. O esquema da bancada de testes pode ser observado na Figura 2.

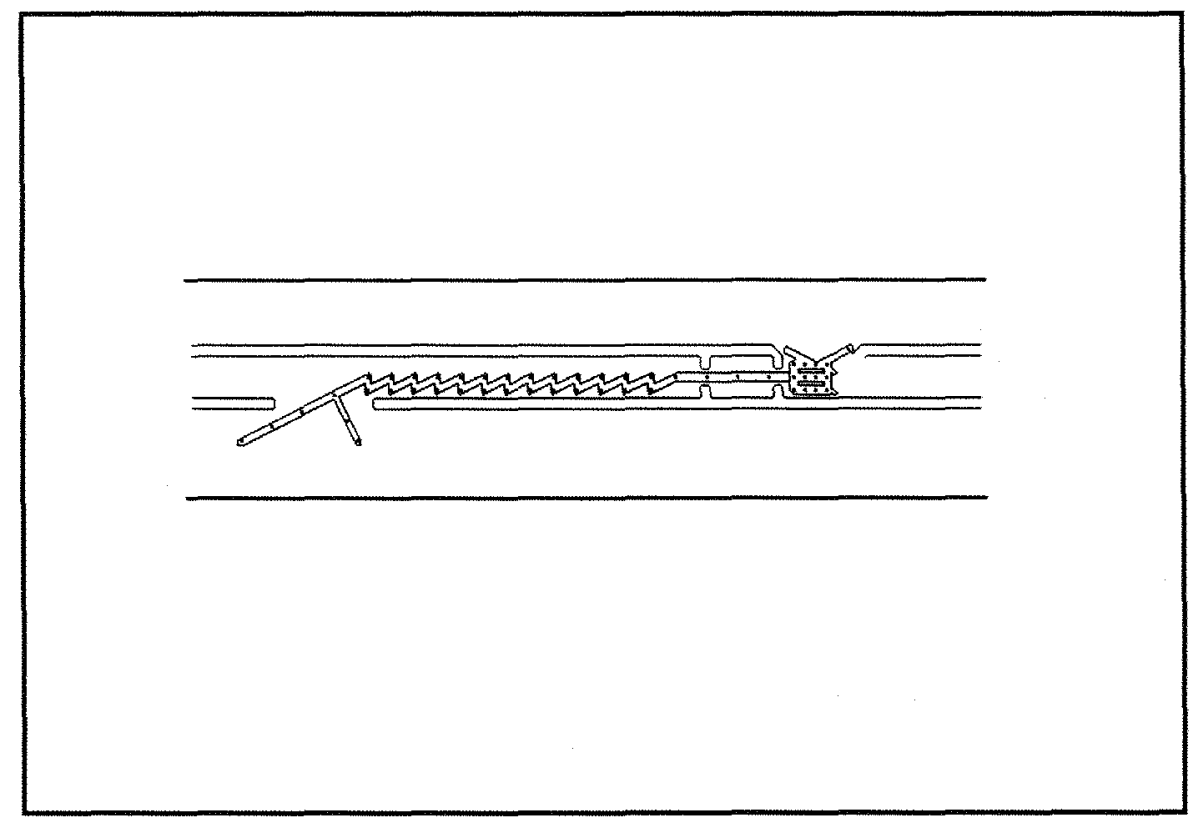

Figura 1 - Esquema do Tubogotejador Rain-Tape

As vazões de cada emissor foram medidas através da coleta de seus volumes por um período de tempo que variou de 7 a 20 min., para cada pressão de entrada, em recipientes de alumínio que interceptavam a água ao mesmo tempo. Em seguida os coletores com água foram pesados e o valor da tara de cada coletor foi descontado deste valor total.

Os emissores tiveram suas vazões medidas com as pressões crescentes e em seguida decrescentes, com o objetivo de verificar se o comportamento das mesmas era semelhante. Assim cada emissor teve duas repetições, totalizando 104 valores de vazão para cada pressão ensaiada. 


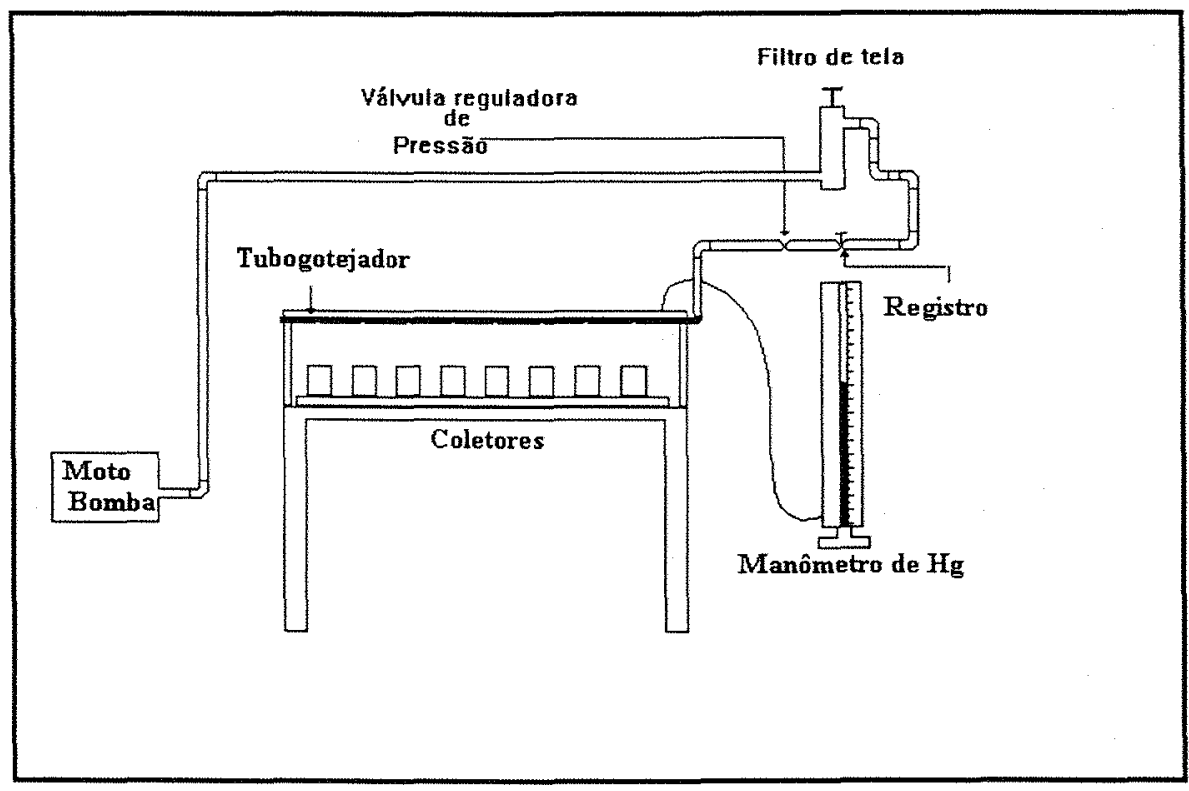

Figura 2 - Esquema da bancada de testes para os ensaios de Uniformidade de vazão.

A vazão média foi obtida através das duas repetições de cada emissor, assim com 52 valores de vazão, correspondentes aos 52 emissores ensaiados, calculou-se a vazão média (qm), desvio padrão da vazão (s) e CVf, para cada pressão considerada. O CVf médio, considerando todas as pressões testadas foi obtido pela média de todos os coeficientes a cada pressão.

A cada ensaio realizado, determinou-se a temperatura da água.

\subsection{Relação Vazão versus Pressão}

A equação característica Vazão versus Pressão para o tubo gotejador RainTape, foi determinada utilizando-se os mesmos dados obtidos para a determinação do CVf. 
A vazão correspondente a cada pressão foi obtida através da média das 52 observações feitas.

Com os pares de valores de vazão e pressão realizou-se a análise de regressão, do tipo potencial, conforme a apresentada por Keller \& Karmeli (1975).

\subsection{Variação do diâmetro com a pressão}

O diâmetro do tubo gotejador foi medido com o auxílio de um paquímetro a cada pressão , em três locais distintos (início, meio e fim da linha-teste) para cada segmento. Assim, a cada pressão obteve-se 12 valores de diâmetro. A média destes diâmetros foi relacionada à pressão correspondente por análise de regressão, ajustouse uma equação potencial.

\subsection{Resistência à pressão}

A resistência do material à pressão foi determinada, submetendo-se o tubo gotejador a pressões internas crescentes e graduais. $O$ acoplamento de um manômetro digital próximo a entrada da linha teste permitiu a leitura da pressão no momento da ruptura.

Foram utilizados 10 segmentos do tubo gotejador com $5 \mathrm{~m}$ de comprimento cada. No final de cada segmento foi instalado uma válvula com fechamento automático. 
A cada aumento de pressão de $1 \mathrm{mca}$, considerou-se um período de tempo para a estabilização da mesma, até que o processo de ruptura se iniciasse.

\subsection{Perda de carga}

Para a determinação da perda de carga ao longo do tubo utilizou-se um segmento de $50 \mathrm{~m}$ de comprimento do tubo gotejador Rain-Tape com todos os emissores vedados.

Foram conectadas tomadas de pressão no início e final da linha-teste, e as perdas de carga medidas com dois manômetros diferenciais com densidades diferentes ( $d=1,8$ e $d=13,6$ ), permitindo assim uma amplitude máxima de perda de carga.

A tomada de pressão no início da linha pode ser observada na Figura 3. O primeiro engate é referente a um manômetro de mercúrio que controlava a pressão de entrada e o segundo, ao manômetro diferencial.

A linha teste foi submetida a 4 pressões diferentes ( 4,6,8 e 9 mca), ajustadas através de uma válvula reguladora de pressão, na sequência havia um medidor de vazão que fornecia a vazão de entrada na linha-teste facilitando a coleta de dados. No final da linha foi instalado um registro para controle da vazão e ajuste da pressão (Figura 4). Para cada pressão determinou-se em torno de 40 pares de valores de vazão e perda de carga.

A água foi coletada no final da linha com o auxílio de um recipiente adequado, e o tempo de coleta cronometrado, determinando-se a vazão. 
Com os dados de vazão e perda de carga, para as quatro pressões ensaiadas, obtidos na linha teste com os gotejadores vedados, por meio de análise de regressão estabeleceu-se o ajuste de 4 equações potencias e uma equação geral com todos os pontos observados.

Em seguida, uma análise estatística foi realizada para verificar se as 4 equações (uma para cada pressão) diferiam da equação geral, ou seja, se apenas uma equação poderia representar a perda de carga.

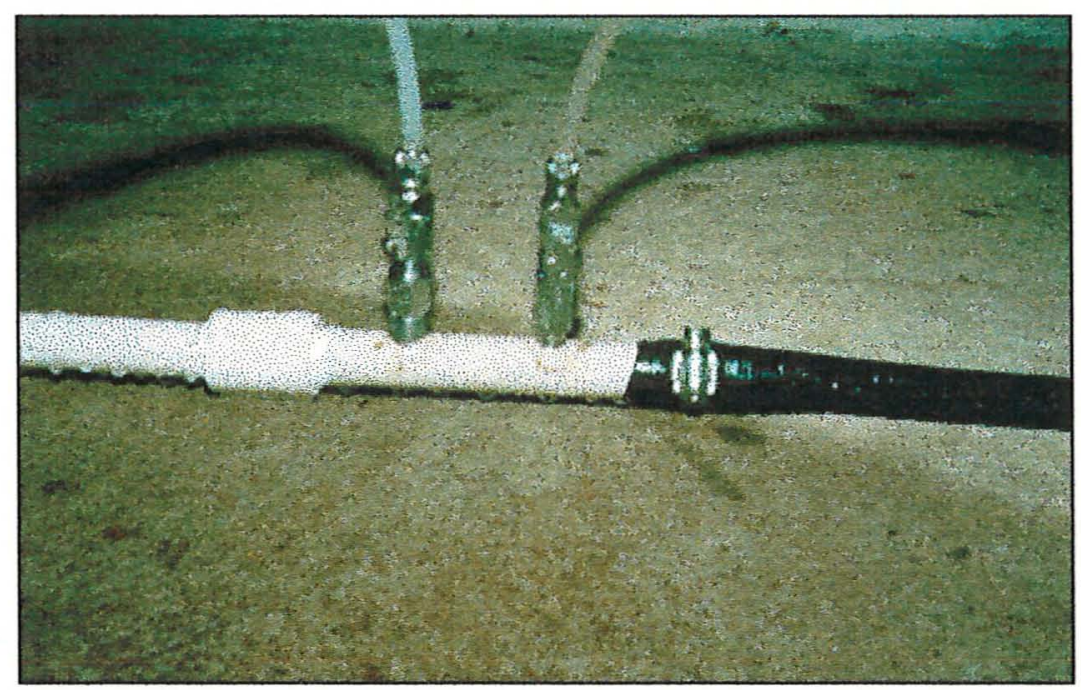

Figura 3 - Detalhe da tomada de pressão

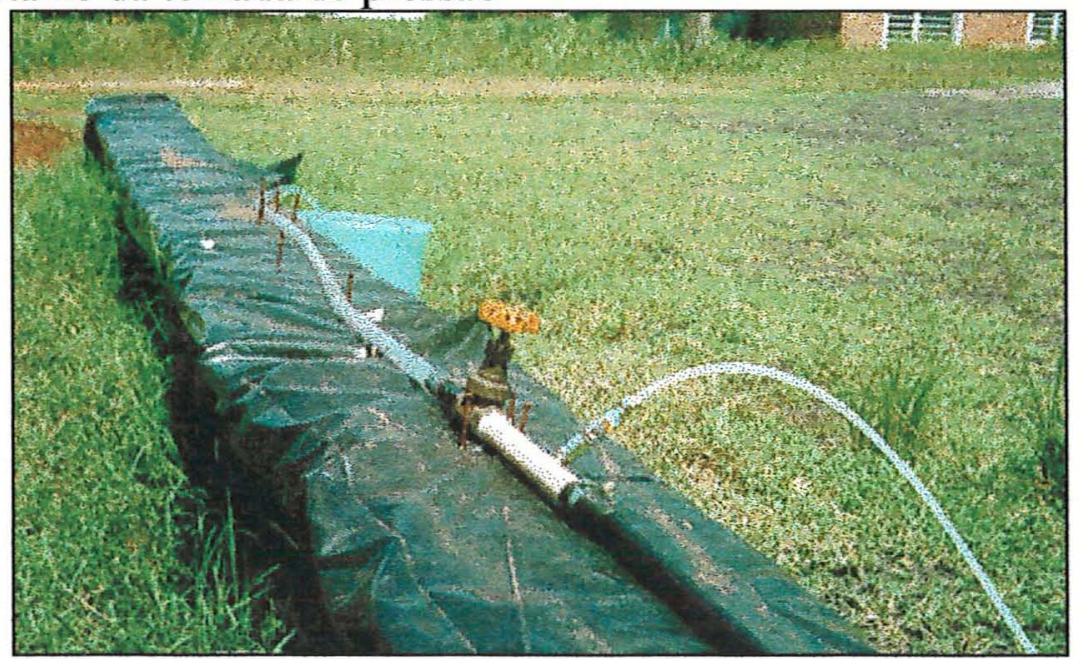

Figura 4 - Final da linha-teste mostrando a tomada de pressão e o registro 


\subsection{Fator de redução da perda de carga (F)}

Objetivando-se determinar o fator de redução de perda de carga proposto por Christiansen (1942), em função do número de saídas e espaçamento entre emissores, elaborou-se uma planilha, cuja sequência de cálculos é demonstrada no fluxograma representado pela Figura 5.

O fator de redução de perda de carga (F) foi calculado, pela razão entre a perda de carga real que ocorre na linha lateral, e a teórica. A sequência de cálculo utilizado na planilha foi o seguinte :

1) acúmulo da perda de carga entre 2 saídas adjacentes, partindo do final para o início da linha, até um certo número de emissores considerados (700 emissores);

2) cálculo da perda de carga na linha lateral considerando toda a vazão, sem saídas laterais;

3) a relação entre a perda de carga acumulada real (ítem 1) e a teórica (ítem 2), fornece o coeficiente de redução de perda de carga " $F$ ".

Foram utilizadas as equações : característica do emissor e a característica de perda de carga, vazão e pressão.

Assim, obteve-se o fator de redução de perda de carga para às pressões de 2 a 10 mca, no máximo até os comprimentos limites dimensionados pelo método estatístico. 


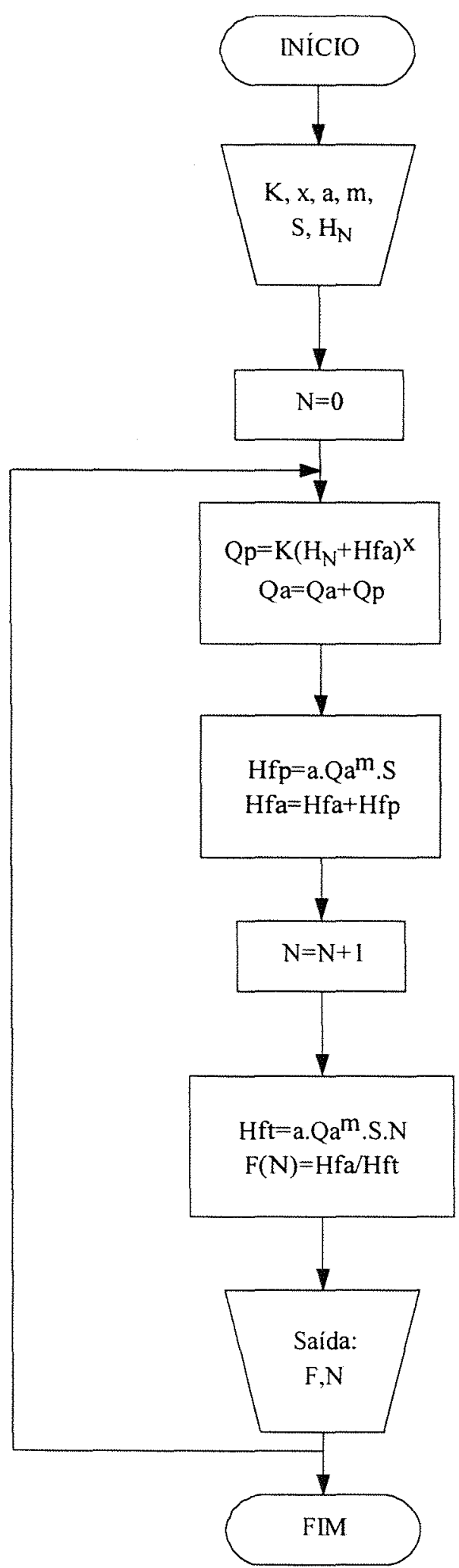

Figura 5 - Fluxograma para a determinação do fator de redução de perda de carga. 


\subsection{Dimensionamento de linhas laterais pelo método estatístico.}

O método de dimensionamento de linhas laterais pelo método estatístico, foi desenvolvido por Anyoji \& Wu (1987) e, diferenciando-se dos outros métodos de dimensionamento, inclui o Coeficiente de variação de fabricação (CVk).

A sequência de cálculos é descrita a seguir:

1) Como o coeficiente de variação da vazão total ( $\mathrm{CVq}$ ) requerido é um dado de entrada, estima-se um coeficiente de variação de vazão ( CVqproc.) próximo ao CVq de entrada, dado pela expressão :

$$
\text { CVqproc. }=\frac{\sqrt{[C V k]^{2}+x^{2} \cdot C V H p^{2}}}{1+\left[C V H p^{2} \cdot\left(0,5 \cdot x^{2}-0,5 \cdot x\right)\right]}
$$

em que :

Cvqproc. - coeficiente de variação de vazão procurado;

CVk - coeficiente de variação de fabricação;

CVHp - coeficiente de variação de pressão permitido;

X - expoente de fluxo do emissor.

O valor de Cvqproc. é obtido por aproximação, incrementando-se o valor de CVHp, até que CVqproc. $\cong C V q$ entrada.

2) O CVHp que resulta na igualdade dos coeficientes de variação de vazão, passa a ser o coeficiente de variação de pressão permitido na linha lateral.

A pressão média na linha é obtida pela seguinte equação : 


$$
H m=\left\{\frac{q m}{K \cdot\left[1+\operatorname{CVHp}^{2} \cdot\left(0,5 \cdot x^{2}-0,5 \cdot x\right)\right]}\right\}^{1 / x}
$$

em que :

Hm - pressão média na linha (mca);

qm - vazão média do emissor $(1 / h)$;

K - constante da equação de fluxo do emissor.

3) Por aproximação faz-se com que o coeficiente de variação de pressão calculado (CVHc - equação 16), aproxime-se do coeficiente de variação de pressão permitido (CVHp). A variável "L" é incrementada com o valor do espaçamento entre emissores (S), alterando o valor de CVHc, até que fique aproximadamente igual ao CVHp. O "L" que resultou na igualdade dos coeficientes da variação de pressão, será o comprimento da linha lateral.

A perda de carga poderá ser calculada de duas formas:

a) Quando a equação de perda de carga é conhecida :

$$
\mathrm{Hf}=\frac{1}{\mathrm{~m}+1} \cdot \mathrm{a} \cdot \mathrm{Qt} \mathrm{t}^{\mathrm{m}} \cdot \mathrm{L}
$$

em que :

m - expoente da vazão da equação ajustada de perda de carga unitária;

a - constante da equação de perda de carga unitária;

Qt - vazão total da linha $(\mathrm{l} / \mathrm{h})$;

L - comprimento da linha lateral (m). 
b) Quando a equação da perda de carga não é conhecida, utiliza-se a equação de DARCY-WEISBACH com " $f$ " de BLASIUS, ou seja :

$$
\mathrm{Hf}=\left(\frac{1}{\mathrm{~m}+1}\right) \cdot 0,00078098 \cdot \mathrm{D}^{-4,75} \cdot \mathrm{Q}^{1,75} \cdot \mathrm{L}
$$

em que :

$\mathrm{Q}$ - vazão total na linha lateral $\left(\mathrm{m}^{3} / \mathrm{s}\right)$;

D - diâmetro interno da linha lateral (m).

A variância da pressão é calculada pela seguinte equação:

a) Para a linha em nível :

$$
\mathrm{VH}=\frac{(\mathrm{m}+1)^{2}}{(2 \mathrm{~m}+3) \cdot(\mathrm{m}+2)^{2}} \cdot \mathrm{Hf}^{2}
$$

em que, VH é a variância da pressão dos emissores ao longo da linha lateral.

b) Para a linha em desnível :

b.1) Aclive :

$$
\mathrm{VH}=\frac{(\mathrm{m}+1)^{2}}{(2 \mathrm{~m}+3) \cdot(\mathrm{m}+2)^{2}} \cdot \mathrm{Hf}^{2}+\frac{1}{12} \Delta \mathrm{Z}^{2}+\frac{\mathrm{m}+1}{(\mathrm{~m}+2) \cdot(\mathrm{m}+3)} \mathrm{Hf} \cdot \Delta \mathrm{Z}
$$

b.2) Declive : 


$$
\mathrm{VH}=\frac{(\mathrm{m}+1)^{2}}{(2 \mathrm{~m}+3) \cdot(\mathrm{m}+2)^{2}} \cdot \mathrm{Hf}^{2}+\frac{1}{12} \Delta \mathrm{Z}^{2}-\frac{\mathrm{m}+1}{(\mathrm{~m}+2) \cdot(\mathrm{m}+3)} \mathrm{Hf} \cdot \Delta \mathrm{Z}
$$

Sendo,

$$
\Delta Z=\text { So. } L
$$

em que :

$\Delta Z$ - Desnível total (m);

So - inclinação considerada $(\mathrm{m} / \mathrm{m})$.

O coeficiente de variação de pressão calculado (CVHc), é dado pela seguinte equação :

$$
\mathrm{CVHc}=\frac{\sqrt{\mathrm{VH}}}{\mathrm{Hm}}
$$

Assim, foram calculados os comprimentos limites para as 9 pressões de entrada ( 2 a $10 \mathrm{mca}$ ) através do método estatístico.

$\mathrm{O}$ valor do $\mathrm{CVq}$ de entrada foi obtido através da relação existente entre a variação de vazão na linha lateral (qvar) e o CVH representada pela equação 7 . Adotou-se como critério de variação de vazão (qvar) máximo permitido na linha lateral de 20 e $10 \%$.

Para a realização deste procedimento foi elaborado um programa de computador, cujo fluxograma é apresentado na Figura 6. 


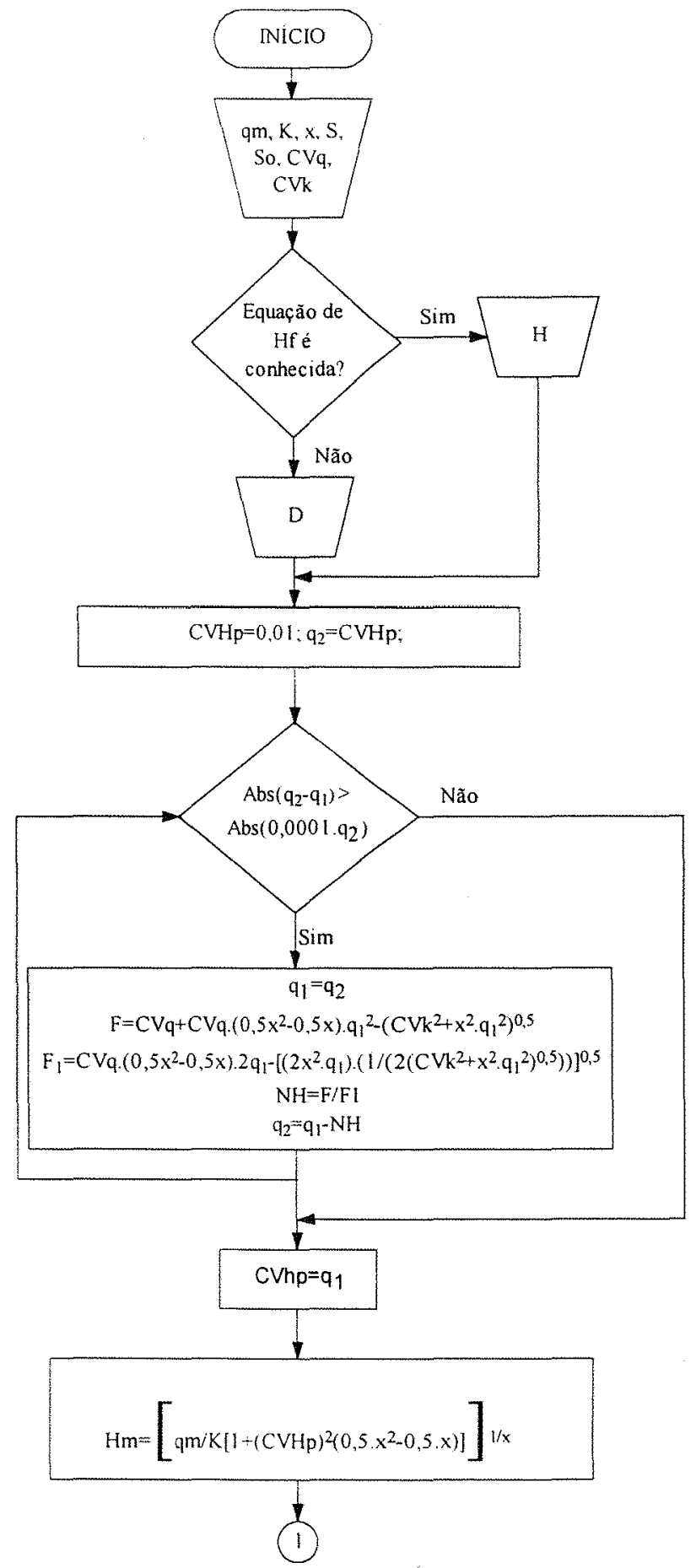

Figura 6 - Fluxograma para dimensionamento de linhas laterais pelo método estatístico 


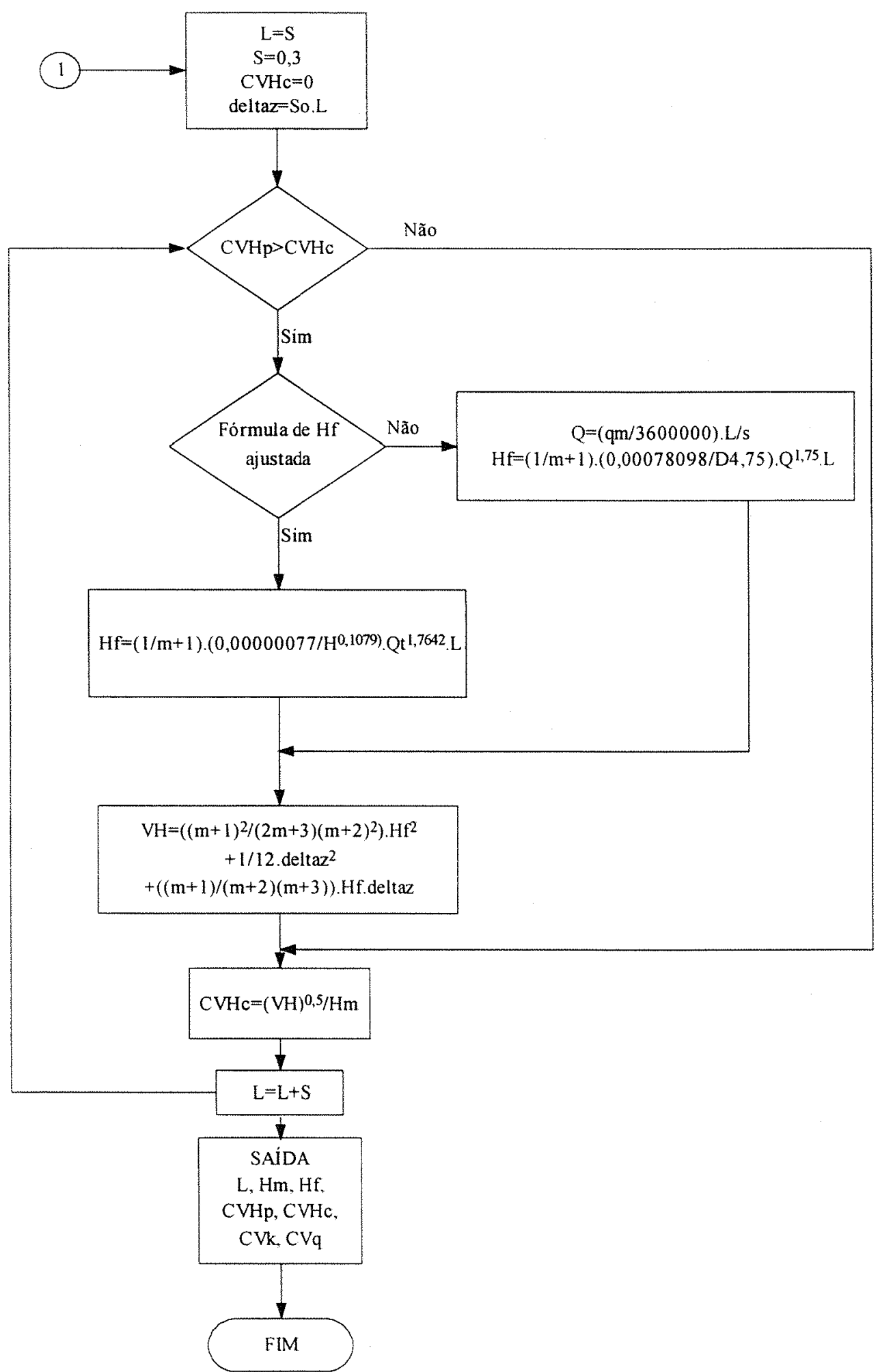

Figura 6 - Continuação 


\section{RESULTADOS E DISCUSSÃO}

\subsection{Uniformidade de vazão}

Pela análise de variância, ao nível de $1 \%$ de significância, não houve diferença estatística entre as vazões determinadas com as pressões crescentes e em seguida com as mesmas pressões decrescentes. Assim, todos os dados de vazão foram utilizados no ajuste da equação característica.

Obteve-se inicialmente a média das vazões para cada gotejador entre a pressão crescente e a decrescente, e em seguida utilizaram-se todos os gotejadores (52), considerando cada um uma repetição. Os valores médios das vazões determinadas em função das pressões são apresentados na Tabela 3.

O efeito dos fatores construtivos para o tubo gotejador Rain-Tape TPC (RainBird), expresso pelo Coeficiente de variação de fabricação (CVf), variou de 1,74 a $2,4 \%$, apresentando um valor médio de $1,97 \%$ para todas as pressões. A Tabela 3 mostra os valores de CVf para cada pressão ensaiada.

A uniformidade do tubo gotejador Rain-Tape é classificada como excelente, segundo Solomon (1979) e a Soil Conservation Service - USDA (1979); e boa segundo a ABNT (1986) e Abréu et al. (1987), concordando com o valor fornecido pelo fabricante que é inferior a $4 \%$. 


\subsection{Relação Vazão versus Pressão}

A relação vazão versus pressão, para o tubo gotejador, foi obtida pelo ajuste da equação potencial com os pares de valores médios de vazão e pressão, indicados também na Tabela 3.

Tabela 3 - Valores de vazão média, devio-padrão e Coeficiente de variação de fabricação do tubo gotejador Rain - Tape.

\begin{tabular}{cccc}
\hline Pressão & Vazão média & $\mathrm{s}$ & CVf \\
\hline (mca) & $(\mathrm{l} / \mathrm{h})$ & $(\mathrm{l} / \mathrm{h})$ & $(\%)$ \\
\hline 2 & 0.633 & 0.015 & 2.4 \\
3 & 0.769 & 0.017 & 2.19 \\
4 & 0.880 & 0.017 & 1.92 \\
5 & 0.974 & 0.018 & 1.88 \\
6 & 1.056 & 0.019 & 1.81 \\
7 & 1.132 & 0.022 & 1.96 \\
8 & 1.199 & 0.023 & 1.88 \\
9 & 1.265 & 0.022 & 1.74 \\
10 & 1.321 & 0.025 & 1.92 \\
\hline Média & & & 1.97 \\
\hline
\end{tabular}

Por análise de regressão, foi obtida a seguinte expressão :

$$
q=0,465 H^{0,4563}
$$

em que :

q - vazão do emissor $(\mathrm{l} / \mathrm{h})$;

$\mathrm{H}$ - pressão na entrada do emissor (mca).

O coeficiente de determinação $\mathrm{r}^{2}$ obtido foi de 0,9996 . O valor do expoente da equação de 0,4563 indica que o regime de escoamento dos emissores é turbulento 
(próximo ao valor de 0,5 ). O coeficiente linear indica a vazão do emissor quando a pressão é igual à unidade (1 m.c.a.).

A Figura 7 mostra a curva característica ajustada pela equação 1. A curva característica fornecida pelo fabricante é apresentada na Figura 8, sendo que as vazões correspondentes foram obtidas por interpolação, e correspondem às mesmas das pressões ensaiadas. $\mathrm{Na}$ Tabela 4 , as diferenças percentuais em relação aos valores obtidos experimentalmente através da equação ajustada podem ser observados.

Observa-se que na faixa de trabalho recomendada pelo fabricante (5 a 10 mca), os valores de vazões encontradas pela equação ajustada experimentalmente foram superiores às do fabricante.

$\mathrm{O}$ efeito da temperatura foi negligenciado, pois a média das temperaturas medidas para todos os ensaios foi de $25,01^{\circ} \mathrm{C}$ com uma variação de $\pm 0,97^{\circ} \mathrm{C}$.

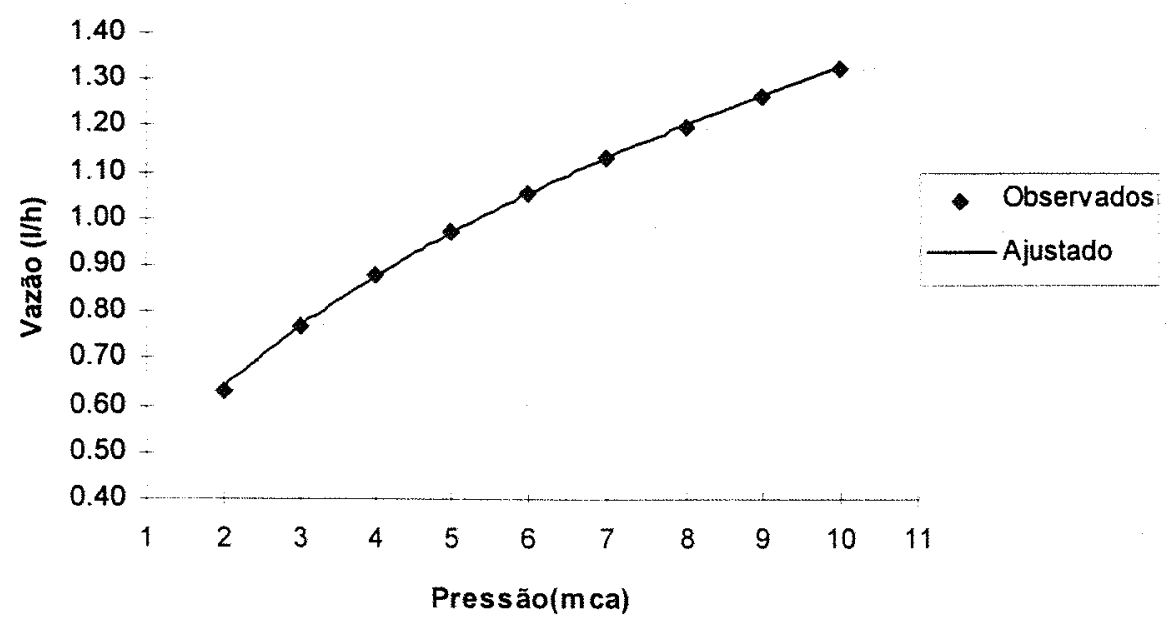

Figura 7 - Curva característica da vazão do tubo gotejador Rain-Tape 


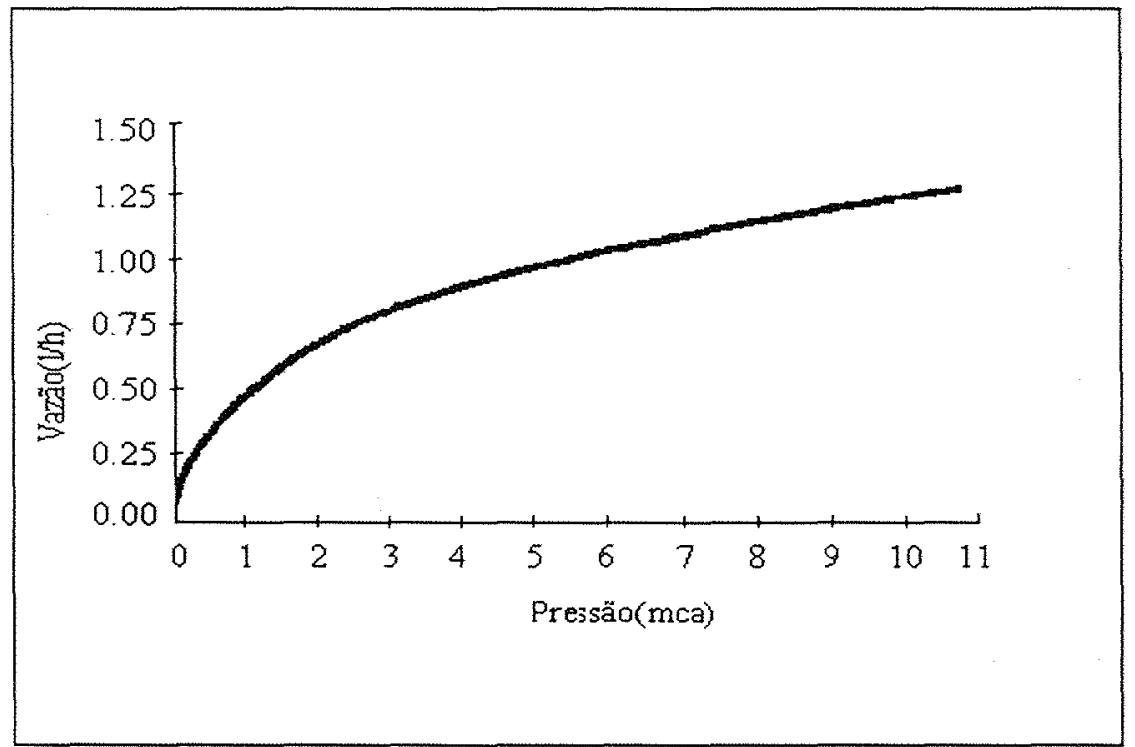

Figura 8 - Curva Característica da vazão fornecida pelo fabricante

Tabela 4 - Vazões fornecidas pelo fabricante e a diferença com as vazões obtidas pela equação ajustada.

\begin{tabular}{cccc}
\hline Pressão & Vazão ajustada & Vazão catálogo & Diferença \\
\hline (mca) & $(\mathrm{l} / \mathrm{h})$ & $(\mathrm{l} / \mathrm{h})$ & $(\%)$ \\
\hline 2 & 0.638 & 0.679 & +6.4 \\
3 & 0.768 & 0.804 & +4.7 \\
4 & 0.875 & 0.893 & +2.1 \\
5 & 0.969 & 0.964 & -0.5 \\
6 & 1.053 & 1.036 & -1.6 \\
7 & 1.130 & 1.107 & -2.1 \\
8 & 1.201 & 1.143 & -5.1 \\
9 & 1.267 & 1.214 & -4.4 \\
10 & 1.331 & 1.250 & -6.4 \\
\hline
\end{tabular}

\subsection{Variação do diâmetro com a pressão}

Os pares de valores de diâmetro e pressão obtidos através da média de 12 repetições podem ser observados na Tabela 5. Após análise de regressão ajustou-se a seguinte equação potencial : 


$$
D i=16,586 H^{0,0055}
$$

em que :

Di - diâmetro interno do tubogotejador (mm);

H - pressão na entrada da linha (mca).

Tabela 5- Valores de diâmetro em função da pressão, para o tubogotejador RainTape.

\begin{tabular}{cc}
\hline Pressão & Diâmetro interno \\
\hline (mca) & $(\mathrm{mm})$ \\
\hline 2 & 16,658 \\
3 & 16,692 \\
4 & 16,708 \\
5 & 16,708 \\
6 & 16,742 \\
7 & 16,767 \\
8 & 16,775 \\
9 & 16,792 \\
10 & 16,808 \\
\hline
\end{tabular}

O valor do coeficiente de determinação foi de 0,9522 e a Figura 9 mostra os pontos observados e a curva ajustada pela equação 18

Apesar da diferença percentual entre o menor e o maior diâmetro não ter sido superior a $1 \%$, os dados foram submetidos a uma análise de variância para verificar se ocorreu diferença significativa.

A análise de variância indicou haver diferença significativa, a 1\% de nível de significância entre as médias dos diâmetros nas diferentes pressões.

Foi realizado um teste de comparação entre médias (teste de Tukey), a 5\% de significância, o qual indicou quais médias diferem entre si (Tabela 6).

Observa-se que existe uma diferenciação entre os grupos seguidos de mesma letra, pois, a medida que a pressão vai aumentando a diferença entre as médias vai tornando-se significativa e o aumento do diâmetro com a pressão não deve ser desconsiderado. 


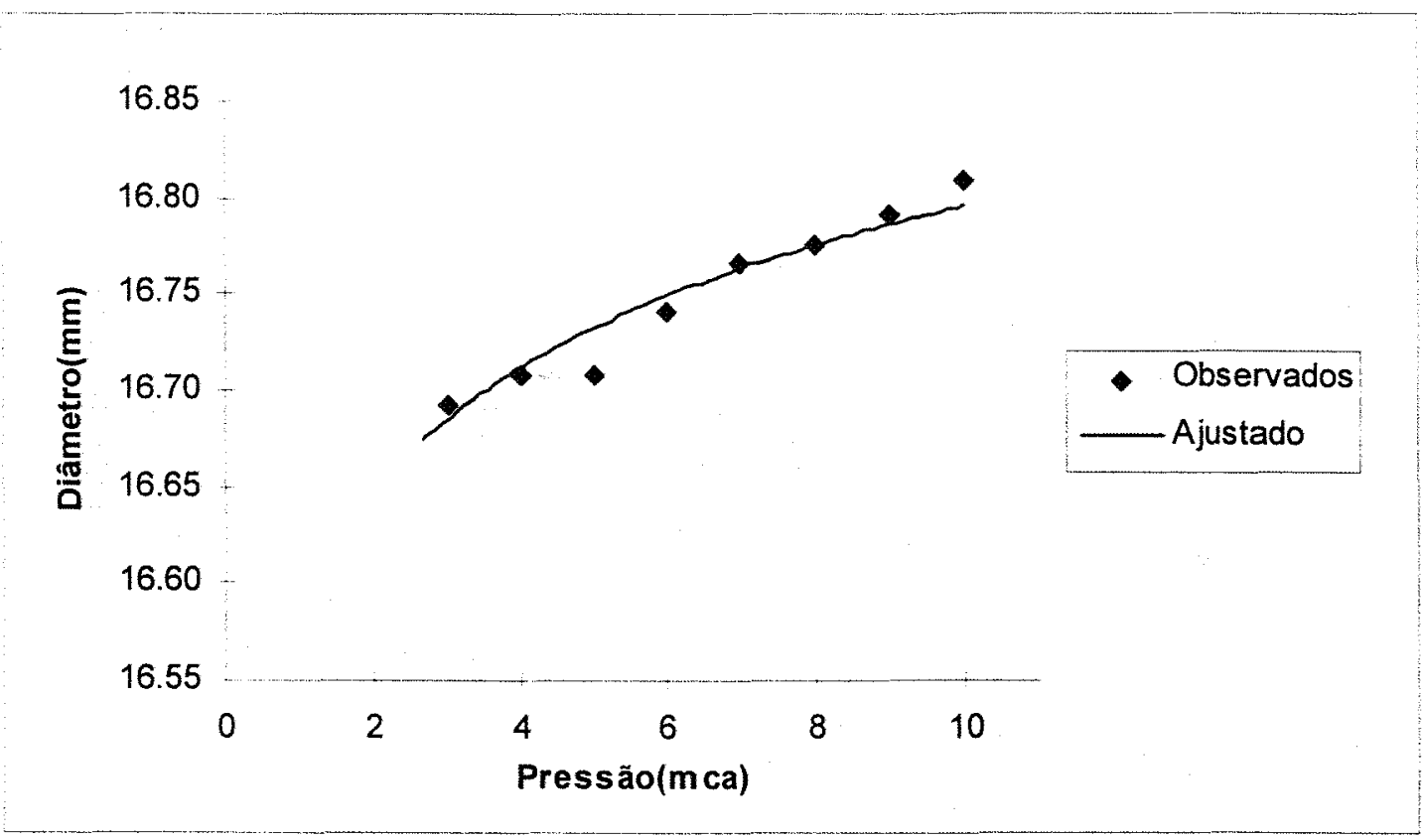

Figura 9 - Diâmetro da tubulação em função da pressão de operação.

Tabela 6 - Resultado da análise de variância para comparação entre médias.

\begin{tabular}{cccc}
\hline Pressão(mca) & $\mathrm{n}$ & Média & Grupos Homogêneos \\
\hline 2 & 12 & 16,658 & $\mathrm{a}$ \\
3 & 12 & 16,692 & $\mathrm{a} \mathrm{b}$ \\
4 & 12 & 16,708 & $\mathrm{a} \mathrm{b} \mathrm{c}$ \\
5 & 12 & 16,708 & $\mathrm{a} \mathrm{b} \mathrm{c}$ \\
6 & 12 & 16,742 & $\mathrm{~b} \mathrm{c} \mathrm{d}$ \\
7 & 12 & 16,767 & $\mathrm{~b} \mathrm{c} \mathrm{d}$ \\
8 & 12 & 16,775 & $\mathrm{c} \mathrm{d}$ \\
9 & 12 & 16,792 & $\mathrm{~d}$ \\
10 & 12 & 16,808 & $\mathrm{~d}$ \\
\hline
\end{tabular}

Médias seguidas de letras minúsculas distintas diferem entre si a 5\% de nível de significância. 


\subsection{Resistência à pressão}

O teste de resistência para o tubo gotejador Rain-Tape apresentou um comportamento regular, ou seja, a pressão de ruptura manteve-se praticamente a mesma a cada teste.

Os valores das pressões de ruptura e o local de ocorrência do mesmo, estão na Tabela 7.

Tabela 7 - Pressões e locais de ruptura do tubo gotejador Rain-Tape.

\begin{tabular}{ccc}
\hline Ensaio & Pressão de ruptura & Distância do início \\
\hline (Número) & (mca) & $(\mathrm{m})$ \\
\hline 1 & 21 & 0.12 \\
2 & 21 & 4.84 \\
3 & 21 & 4.25 \\
4 & 21 & 1.22 \\
5 & 21 & 4.52 \\
6 & 21 & 4.84 \\
7 & 21 & 4.25 \\
8 & 21 & 2.26 \\
9 & 21 & 0.07 \\
10 & 21 & 4.25 \\
\hline
\end{tabular}

A partir da pressão de 17 mca todo o tubo começa a deformar-se levemente, acentuando esta deformação a cada incremento de 1 mca na pressão.

As deformações ocorrem ao longo dos 5 metros de tubo gotejador, até o momento em que se observa uma dilatação maior e rapidamente a formação de uma "vesícula", com parede pouco espessa que se rompe a seguir. A Figura 10 mostra a sequência do processo até o momento da ruptura.

A ruptura ocorreu em locais distintos ao longo do tubo onde a parede do mesmo torna-se mais frágil devido à pressão. Este processo repetiu-se a cada teste e sempre o dano ocorreu na parede do tubo gotejador, nunca nos emissores. Mesmo na 
pressão mais elevada (21 mca), a água permaneceu gotejando, não sendo expelida na forma de jato.

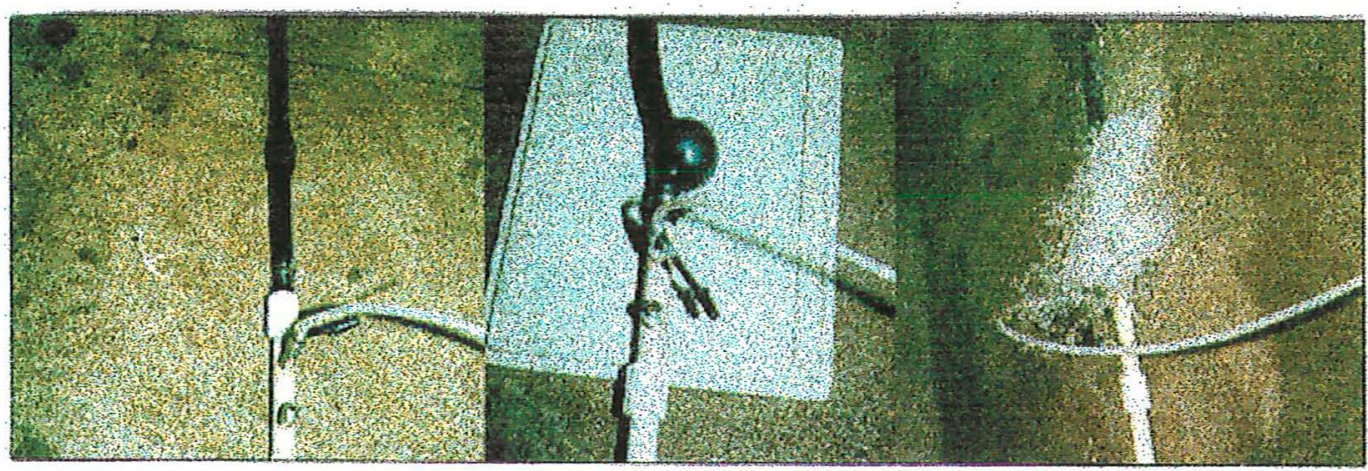

Figura 10 - Sequência do processo de ruptura do tubogotejador Rain-Tape.

\subsection{Perda de carga}

Com os dados de vazão e perda de carga para 4 pressões consideradas $(4,6,8$ e 9 mca), ajustou-se 4 equações potenciais :

$$
\begin{array}{ll}
\mathrm{J}_{4}=6,30 \times 10^{-7} \cdot \mathrm{Qt}^{\mathrm{t}, 7716} & \mathrm{r}^{2}=0,9998 \\
\mathrm{~J}_{6}=7,25 \times 10^{-7} \cdot \mathrm{Qt}^{\mathrm{t}, 7431} & \mathrm{r}^{2}=0,9995 \\
\mathrm{~J}_{8}=7,19 \times 10^{-7} \cdot \mathrm{Qt}^{1,7398} & \mathrm{r}^{2}=0,9995 \\
\mathrm{~J}_{9}=6,87 \times 10^{-7} \cdot \mathrm{Qt}^{\mathrm{t}^{1,747}} & \mathrm{r}^{2}=0,9995
\end{array}
$$

em que :

Qt- vazão total $(1 / h)$;

$\mathrm{J}_{4}$ - perda de carga unitária à pressão de 4 m.c.a.;

$\mathrm{J}_{6}$ - perda de carga unitária à pressão de 6 m.c.a.;

$\mathrm{J}_{8}$ - perda de carga unitária à pressão de 8 m.c.a.;

$\mathrm{J}_{9}$ - perda de carga unitária à pressão de 9 m.c.a. 
Objetivando verificar a possibilidade da perda de carga ser estimada por uma única equação para as diferentes pressões, ajustou-se com todos os valores obtidos uma única equação :

$$
J=7,21 \times 10^{-7} \cdot Q t^{1,7423}
$$

em que :

$J$ - perda de carga unitária $(\mathrm{m} / \mathrm{m})$.

O ajuste apresenta um coeficiente $\mathrm{r}^{2}$ de 0,9987 .

As 5 equações foram submetidas a um teste de comparação de regressões (teste Fz) proposto por Zar (1974), onde verficou-se a possibilidade das equações não diferirem entre si, ou seja, uma única equação poderia substituir as anteriores.

A Tabela 8 mostra a soma dos quadrados dos resíduos de cada equação e o número de graus de liberdade do resíduo que foram usados para o cálculo do $\mathrm{Fz}$ estimado.

Tabela 8 - Valores de soma dos quadrados e grau de liberdade do resíduo da análise de variância, para determinação de Fz.

\begin{tabular}{cccc}
\hline $\begin{array}{c}\text { Equação } \\
(\mathrm{k})\end{array}$ & $\begin{array}{c}\text { número } \\
\text { de } \\
\text { obs.(n) }\end{array}$ & $\begin{array}{c}\text { Soma dos quadrados dos } \\
\text { resíduos(SQi) }\end{array}$ & $\begin{array}{c}\text { Grau de liberdade do } \\
\text { resíduo(GLi) }\end{array}$ \\
\hline 1 & 56 & 0.000003 & 55 \\
2 & 33 & 0.000016 & 32 \\
3 & 38 & 0.000039 & 37 \\
4 & 39 & 0.000049 & 38 \\
$\sum$ & & 0.000107 & 162 \\
Geral & 166 & 0.00031 & 165 \\
\hline
\end{tabular}

Para verificar se existe diferença significativa entre a equação geral (equação 23) e as demais equações para diferentes pressões aplicou-se o seguinte teste Fz: 


$$
F z=\frac{\frac{S Q g-\sum_{i=1}^{n} S Q i}{2(k-1)}}{\frac{\sum_{i=1}^{n} S Q i}{\sum_{i=1}^{n} G L i}}
$$

onde :

SQrg - soma dos quadrados dos desvios da equação geral (obtido na análise de variância da respectiva regressão);

k - número de equações comparadas com a equação geral;

SQi - soma dos quadrados dos desvios das equações comparadas com a equação geral (obtidos através da análise de variância de cada regressão);

GLi - grau de liberdade do resíduo das equações comparadas com a equação geral (obtidos através da análise de variância de cada regressão).

Tem-se, portanto :

$$
F z=\frac{\frac{0,00031-0,000107}{2(4-1)}}{\frac{0,000107}{162}}=51,22 * *
$$

Como o valor estimado foi superior ao tabelado, para 5 e $1 \%$ de nível de significância, existe diferença significativa entre a equação geral e as demais equações, não podendo a equação 23 representar as demais.

Como. existe efeito significativo da pressão sobre o diâmetro interno do conduto com a elevação da pressão, a perda de carga também é afetada com este efeito. Assim, deveria ser ajustado um modelo que considerasse a vazão e a pressão ou a vazão e o diâmetro interno na estimativa da perda de carga. 
Ajustou-se duas equações de perda de carga, uma incluindo a pressão e outra o diâmetro interno como variáveis, ou seja :

$$
J=7,1509 \times 10^{-4} \cdot Q^{1,7359} \cdot D^{-4,7332}
$$

em que :

$Q$ - vazão total na linha $\left(\mathrm{m}^{3} / \mathrm{s}\right)$;

D- diâmetro interno da tubulação (m).

$$
J=7,7 \times 10^{-7} \cdot Q t^{1,7642} \cdot H^{-, 1079}
$$

em que :

Qt - vazão total na linha $(1 / h)$;

H - pressão de entrada (mca).

Os coeficientes de determinação $r^{2}$ para as equações (25) e (26) foram respectivamente, 0,9994 e 0,9998.

Observa-se que a equação 25 é muito semelhante a equação universal de perda de carga com " $\mathrm{f}$ " de Blasius :

$$
J=7,8048 \times 10^{-4} \cdot Q^{1,75} \cdot D^{-4,75}
$$

em que :

$\mathrm{Q}$ - vazão total na linha $\left(\mathrm{m}^{3} / \mathrm{s}\right)$;

$\mathrm{D}$ - diâmetro interrno $(\mathrm{m})$.

Com o objetivo de verificar se as perdas de carga obtidas pelas equações 25 26 e 27 e os valores medidos experimentalmente diferiam entre si, aplicou-se o teste F. 
A análise de variância entre a perda de carga medida e estimada pelas diferentes equações, indicou não haver diferença significativa entre elas a $1 \%$ de nível de significância. Portanto, qualquer uma das equações $(25,26$ e 27$)$ pode ser utilizada para o cálculo da perda de carga linear.

Optou-se pela equação 26 , pois considera-se a variação do diâmetro com a pressão.

\subsection{Fator de redução de perda de carga}

Através da planilha cujo fluxograma foi mostrado na Figura 5, determinaramse os valores dos coeficientes de redução de perda de carga (F) para o tubo gotejador Rain-Tape, em função do número de emissores e pressão de serviço, para um espaçamento de $0,30 \mathrm{~m}$ entre emissores.

Como o dimensionamento das linhas laterais foi realizado através do método estatístico, nenhum critério de variação de vazão foi adotado para o cálculo de $\mathrm{F}$. Considerou-se como limite o número de emissores correspondente pelo menos ao máximo comprimento da linha lateral obtido pelo método estatístico.

Utilizaram-se para o cálculo do "F" as equações experimentais de vazão versus pressão (equação 17) e perda de carga versus vazão e pressão (equação 26).

A Tabela 9 mostra os valores de "F" para as 9 pressões estudadas em função do número de emissores.

Observa-se que dentro de uma mesma pressão os valores de "F"decrescem com o aumento do número de emissores e também decrescem com o aumento da pressão. Este decréscimo no valor de "F" com o aumento da pressão se deve provavelmente ao aumento do diâmetro interno em função da mesma, influenciando assim na perda de carga. Andrade (1990), observou um aumento dos valores de "F" 
com o aumento da pressão para um mesmo número de emissores, estando também avaliando também tubos flexíveis.

Tabela 9 - Fator de redução de perda de carga $(\mathrm{F})$ para o tubogotejador Rain-Tape, com espaçamento entre emissores de $0,30 \mathrm{~m}$, em função do número de saídas $(\mathrm{N})$.

\begin{tabular}{|c|c|c|c|c|c|c|c|c|c|}
\hline \multirow[t]{2}{*}{$\mathrm{N}$} & \multicolumn{9}{|c|}{ Pressão (mca) } \\
\hline & 2 & 3 & 4 & 5 & 6 & 7 & 8 & 9 & 10 \\
\hline 1 & 1 & 1 & 1 & 1 & 1 & 1 & 1 & 1 & 1 \\
\hline 2 & 0.6472 & 0.6258 & 0.6112 & 0.6001 & 0.5913 & 0.5840 & 0.5777 & 0.5723 & 0.5675 \\
\hline 3 & 0.5443 & 0.5231 & 0.5086 & 0.4976 & 0.4889 & 0.4846 & 0.4754 & 0.4700 & 0.4652 \\
\hline 4 & 0.4958 & 0.4755 & 0.4616 & 0.4511 & 0.4428 & 0.4358 & 0.4299 & 0.4247 & 0.4202 \\
\hline 5 & 0.4675 & 0.4480 & 0.4347 & 0.4246 & 0.4166 & 0.4099 & 0.4042 & 0.3993 & 0.3949 \\
\hline 6 & 0.4491 & 0.4302 & 0.4173 & 0.4075 & 0.3997 & 0.3932 & 0.3877 & 0.3829 & 0.3786 \\
\hline 7 & 0.4362 & 0.4177 & 0.4051 & 0.3955 & 0.3879 & 0.3816 & 0.3762 & 0.3715 & 0.3674 \\
\hline 8 & 04265 & 0.4084 & 0.3960 & 0.3867 & 0.3792 & 0.3730 & 0.3677 & 0.3631 & 0.3590 \\
\hline 9 & 0.4191 & 0.4013 & 0.3891 & 0.3799 & 0.3725 & 0.3664 & 0.3612 & 0.3567 & 0.3527 \\
\hline 10 & 0.4132 & 0.3956 & 0.3836 & 0.3745 & 0.3629 & 0.3612 & 0.3561 & 0.3516 & 0.3476 \\
\hline 11 & 0.4084 & 0.3910 & 0.3791 & 0.3701 & 0.3594 & 0.3570 & 0.3519 & 0.3474 & 0.3534 \\
\hline 12 & 0.4044 & 0.3872 & 0.3754 & 0.3665 & 0.3563 & 0.3534 & 0.3484 & 0.3440 & 0.3401 \\
\hline 13 & 0.4011 & 0.3840 & 0.3722 & 0.3634 & 0.3538 & 0.3505 & 0.3455 & 0.3411 & 0.3373 \\
\hline 14 & 0.3982 & 0.3812 & 0.3696 & 0.3608 & 0.3516 & 0.3480 & 0.3430 & 0.3387 & 0.3349 \\
\hline 15 & 0.3957 & 0.3788 & 0.3673 & 0.3585 & 0.3496 & 0.3458 & 0.3408 & 0.3365 & 0.3327 \\
\hline 16 & 0.3936 & 0.3768 & 0.3653 & 0.3566 & 0.3479 & 0.3439 & 0.3390 & 0.3347 & 0.3309 \\
\hline 17 & 0.3917 & 0.3749 & 0.3635 & 0.3548 & 0.3464 & 0.3422 & 0.3373 & 0.3331 & 0.3293 \\
\hline 18 & 0.3900 & 0.3733 & 0.3619 & 0.3533 & 0.3451 & 0.3407 & 0.3359 & 0.3316 & 0.3279 \\
\hline 19 & 0.3885 & 0.3719 & 0.3605 & 0.3519 & 0.3439 & 0.3394 & 0.3346 & 0.3303 & 0.3266 \\
\hline 20 & 0.3871 & 0.3706 & 0.3593 & 0.3507 & 0.3428 & 0.3382 & 0.3334 & 0.3292 & 0.3255 \\
\hline 25 & 0.3820 & 0.3657 & 0.3545 & 0.3461 & 0.3393 & 0.3337 & 0.3289 & 0.3248 & 0.3211 \\
\hline 30 & 0.3786 & 0.3624 & 0.3513 & 0.3430 & 0.3363 & 0.3307 & 0.3260 & 0.3219 & 0.3183 \\
\hline 35 & 0.3762 & 0.3601 & 0.3491 & 0.3408 & 0.3341 & 0.3286 & 0.3239 & 0.3198 & 0.3162 \\
\hline 40 & 0.3743 & 0.3583 & 0.3474 & 0.3391 & 0.3325 & 0.3270 & 0.3223 & 0.3183 & 0.3147 \\
\hline 50 & 0.3718 & 0.3559 & 0.3450 & 0.3368 & 0.3302 & 0.3248 & 0.3202 & 0.3161 & 0.3125 \\
\hline 60 & 0.3701 & 0.3543 & 0.3434 & 0.3353 & 0.3287 & 0.3233 & 0.3187 & 0.3147 & 0.3111 \\
\hline 70 & 0.3689 & 0.3531 & 0.3423 & 0.3342 & 0.3276 & 0.3222 & 0.3176 & 0.3136 & 0.3101 \\
\hline 80 & 0.3679 & 0.3522 & 0.3414 & 0.3333 & 0.3268 & 0.3214 & 0.3168 & 0.3128 & 0.3093 \\
\hline 90 & 0.3672 & 0.3515 & 0.3407 & 0.3326 & 0.3262 & 0.3208 & 0.3162 & 0.3122 & 0.3087 \\
\hline 100 & 0.3666 & 0.3509 & 0.3402 & 0.3321 & 0.3256 & 0.3203 & 0.3157 & 0.3117 & 0.3082 \\
\hline 120 & 0.3656 & 0.3500 & 0.3393 & 0.3312 & 0.3248 & 0.3195 & 0.3149 & 0.3109 & 0.3074 \\
\hline 140 & 0.3648 & 0.3492 & 0.3386 & 0.3306 & 0.3241 & 0.3188 & 0.3143 & 0.3103 & 0.3068 \\
\hline 160 & 0.3641 & 0.3486 & 0.3380 & 0.3300 & 0.3236 & 0.3183 & 0.3137 & 0.3098 & 0.3063 \\
\hline 180 & 0.3634 & 0.3480 & 0.3374 & 0.3294 & 0.3231 & 0.3178 & 0.3132 & 0.3093 & 0.3058 \\
\hline 200 & 0.3627 & 0.3474 & 0.3369 & 0.3289 & 0.3226 & 0.3173 & 0.3128 & 0.3089 & 0.3054 \\
\hline 250 & 0.3609 & 0.3458 & 0.3354 & 0.3276 & 0.3213 & 0.3161 & 0.3116 & 0.3077 & 0.3043 \\
\hline 300 & 0.3588 & 0.3440 & 0.3338 & 0.3260 & 0.3198 & 0.3147 & 0.3103 & 0.3065 & 0.3031 \\
\hline 350 & 0.3562 & 0.3417 & 0.3317 & 0.3242 & 0.3181 & 0.3131 & 0.3087 & 0.3050 & 0.3016 \\
\hline 400 & 0.3532 & 0.3391 & 0.3294 & 0.3220 & 0.3160 & 0.3111 & 0.3069 & 0.3032 & 0.2999 \\
\hline 450 & 0.3496 & 0.3360 & 0.3266 & 0.3194 & 0.3136 & 0.3088 & 0.3047 & 0.3011 & 0.2979 \\
\hline 500 & 0.3455 & 0.3324 & 0.3234 & 0.3164 & 0.3109 & 0.3062 & 0.3022 & 0.2987 & 0.2956 \\
\hline 550 & 0.3410 & 0.3285 & 0.3198 & 0.3131 & 0.3077 & 0.3032 & 0.2994 & 0.2960 & 0.2930 \\
\hline 600 & 0.3360 & 0.3241 & 0.3158 & 0.3094 & 0.3043 & 0.2999 & 0.2962 & 0.2930 & 0.2901 \\
\hline 650 & 0.3307 & 0.3194 & 0.3115 & 0.3054 & 0.3005 & 0.2964 & 0.2928 & 0.2897 & 0.2869 \\
\hline 700 & 0.3251 & 0.3144 & 0.3069 & 0.3012 & 0.2965 & 0.2925 & 0.2891 & 0.2861 & 0.2835 \\
\hline
\end{tabular}




\subsection{Dimensionamento das linha laterais pelo método estatístico}

Adotou-se uma variação de vazão (qvar) admissível entre o primeiro e o último emissor de 10 e 20\%, que correspondem a um CVq de 2,64 e 4,1\% respectivamente, considerando que o $\mathrm{CVq}$ é um dado de entrada no programa.

Através do programa elaborado com base no fluxograma da Figura 6, foram obtidos os comprimentos limites para o tubo gotejador Rain-Tape considerando os critérios de variação de vazão (10 e $20 \%$ ), 9 pressões ( 2 a 10 mca) e a linha lateral em nível, aclive ( 1 e $2 \%$ ) e declive (1,2 e 3\%) como mostra a Tabela 10.

Tabela 10 - Comprimentos máximos da linha lateral para o Tubo gotejador RainTape.

\begin{tabular}{ccccccccccc}
\hline qvar & Desnível & \multicolumn{10}{c}{ Pressão de entrada } \\
\cline { 2 - 11 } & & 2 & 3 & 4 & 5 & 6 & 7 & 8 & 9 & 10 \\
\hline$(\%)$ & $(\%)$ & & & & 7 & (mca) & & & & \\
\hline 10 & +2 & 13.2 & 19.5 & 25.8 & 31.5 & 37.2 & 42.6 & 47.4 & 51.9 & 56.1 \\
20 & +2 & 27.0 & 39.3 & 50.7 & 60.6 & 69.6 & 77.1 & 83.7 & 89.7 & 94.8 \\
\hline 10 & +1 & 25.5 & 36.9 & 46.5 & 54.6 & 61.2 & 66.9 & 71.7 & 75.9 & 79.5 \\
20 & +1 & 50.1 & 67.8 & 80.7 & 90.6 & 98.4 & 104.7 & 109.8 & 114. & 117.9 \\
\hline 10 & 0 & 92.1 & 96.3 & 99.3 & 101.7 & 103.8 & 105.6 & 107.1 & 108.6 & 109.8 \\
20 & 0 & 120 & 125.4 & 129.3 & 132.6 & 135.3 & 137.7 & 139.5 & 141.3 & 143.1 \\
\hline 10 & -1 & 27.0 & 43.5 & 71.1 & 144.3 & 143.1 & 141.6 & 140.4 & 139.5 & 138.6 \\
20 & -1 & 63.0 & 177.6 & 174.9 & 172.2 & 170.4 & 169.2 & 168.3 & 167.7 & 167.4 \\
\hline 10 & -2 & 13.2 & 20.10 & 27.0 & 34.2 & 42.3 & 51.9 & 63.9 & 90.6 & 156.9 \\
20 & -2 & 27.9 & 42.9 & 60.6 & 87.6 & 193.2 & 192.9 & 191.4 & 189.9 & 188.4 \\
\hline 10 & -3 & 9.0 & 13.2 & 17.7 & 22.2 & 27.0 & 31.8 & 36.6 & 42.0 & 48.0 \\
20 & -3 & 18.3 & 27.6 & 37.5 & 48.0 & 59.7 & 74.1 & 95.7 & 202.5 & 203.1 \\
\hline
\end{tabular}

Observa-se que quando se considera a linha lateral em declive, ocorre em dadas pressões, um aumento considerável do comprimento da linha lateral e em seguida, nas pressões subsequentes sua estabilização. Isto pode ser verificado por exemplo na pressão de 8 para 9 mca, com $3 \%$ de declividade e $20 \%$ de quar, onde o 
comprimento da linha lateral aumentou de $95,7 \mathrm{~m}$ na pressão de 8 mca para $202,5 \mathrm{~m}$ na pressão de 9 mca.

Provavelmente este aumento brusco ocorreu devido a uma mudança no tipo de perfil da linha lateral, pois dois fatores interagiram para isto, a perda de carga que é função da vazão e da pressão, e a declividade. Verificou-se na sequência de cálculos do programa, que nestes casos a perda de carga e o desnível total vão aumentando gardativamente até o momento em que o desnível fica muito superior a perda de carga e o CVH começa a diminuir. O CVH permanece decrescente até o momento em que a perda de carga começa a aumentar mais que o desnível, ocorrendo a partir daí a inversão do $\mathrm{CVH}$ que começa a aumentar novamente. A partir daí a perda de carga supera o desnível e o CVH continua aumentando até atingir o valor delimitado pelo programa. 


\section{CONCLUSÕES}

Baseando-se na metodologia utilizada e nas condições da realização dos ensaios conclui-se que :

- O tubogotejador estudado apresenta uniformidade de vazão classificada como excelente $(1,97 \%)$.

- O regime de escoamento do emissor é turbulento por apresentar o expoente $\mathrm{x}=0,4563$.

- As vazões ajustadas pela equação característica obtida, diferiram das vazões fornecidas pelo fabricante de $+6,4 \%$ a $-6,4 \%$ conforme aumentou-se a pressão de 2 para 10 mca.

- A análise de variância indicou haver influência da pressão sobre o diâmetro interno da tubulação, ou seja, com o aumento da pressão o diâmetro aumenta.

- O teste de resistência à pressão demonstrou que o tubogotejador Rain-tape rompe à pressão de 21 mca. O local da ruptura foi variável ao longo da linha, e sempre na parede do tubogotejador, nunca no emissor.

- Os valores de perda de carga determinados experimentalmente não diferiram significativamente pelo teste $\mathrm{F}$, a $1 \%$ de probabilidade, dos valores calculados pela equação universal, e pelas equações ajustadas (de perda de carga, vazão e pressão; e perda de carga, vazão e diâmetro).

- Os valores dos coeficientes de redução de perda de carga $(F)$, decresceram com o aumento da pressão para um mesmo número de emissores.

- O comprimento máximo da linha lateral foi de 203,1 m para um declive de $3 \%$, quar de $20 \%$ e pressão de serviço de 10 m.c.a. 


\section{REFERÊNCIAS BIBLIOGRÁFICAS}

ABRÉU, J.M.H.; LÓPEZ, J.R.; REGALADO, A.P.; HERNÁNDEZ, J.F. El riego

localizado. Madrid, Espanha: Instituto Nacional de Investigações Agrárias, 1987. $317 \mathrm{p}$.

ANDRADE, D.V. de. Avaliação hidraúlica de tubos flexíveis de polietileno perfurados a laser utilizados na irrigação. Piracicaba, 1990. 147p. Dissertação (M.S.)-Escola Superior de Agricultura "Luiz de Queiroz", Universidade de São Paulo.

ANYOJI, H; WU, I.P. Statistical approach for drip lateral design. Transactions of the ASAE, v.30, n.1, p.187-92, jan-feb. 1987.

ASSOCIAÇÃO BRASILEIRA DE NORMAS TÉCNICAS. Requisitos mínimos para elaboração de projeto de sistema de irrigação localizada, PNBR 12:0208-022. São Paulo, 1986. 8p.

ASSOCIAÇÃO BRASILEIRA DE NORMAS TÉCNICAS. Emissores para sistemas de irrigação localizada - avaliação das características operacionais, PNBR 12:02-08-021. São Paulo, 1986. 7p. 
ASSY, T.M. O emprego da fórmula universal de perda de carga e as limitações das fórmulas empíricas. São Paulo: CETESB, 1977. 64p.

BERNARDO, S. Manual de irrigação. 5.ed. Viçosa: Imprensa Universitária da Universidade Federal de Viçosa, 1989. 596p.

BEZDEK, J.C.; SOLOMON, K. Approximating friction factors for trickle tubing. Journal of the Irrigation and Drainage Division, v.104, n.4, p.351-9, dec. 1978.

BOTREL, T.A. Hidráulica de microaspersores e linhas laterais para irrigação localizada. Piracicaba, 1984. 78p. Dissertação (M.S.)-Escola Superior de Agricultura "Luiz de Queiroz", Universidade de São Paulo.

BRALTS, V.F.; WU, I.; GITLIN, H.M. Manufacturing variation and drip irrigation uniformity. Transactions of the ASAE, v.24, n.1, p.113-9, jan-feb. 1981.

BRAUD, H.J.; SOOM, A.M. Trickle irrigation lateral design on sloping fields. Transactions of the ASAE, v.24, n.4, p.941-4, july-aug. 1981.

CHRISTIANSEN, J.E. Irrigation by sprinkling. Berkeley: Califórnia Agricultural Experiment Station, 1942. 124p. (Bulletin 670).

FARIA, M.A. Características hidráulicas do microgotejador IRTEC e da linha lateral de irrigação. Viçosa, 1981. 78p. Dissertação (M.S.)- Universidade Federal de Viçosa. 
GILLARD, Y.; KRISTAL, L.; ZANKER, K. Hidraulic a mechanical properties of drippers. In: International Drip Irrigation Congress, 2, Riverside, 1974. Proccedings: $p .311-6$.

HOWELL, T.A.; HILER, E.A. Designing trickle irrigations laterals for uniformity. Journal of the Irrigation and Drainage Division, v.100, n.4, p.443-54, dec. 1974.

HOWELL, T.A.; BARINAS, F.A. Pressure losses across trickle irrigation fittings and emitters. Transactions of the ASAE, v.23, n.4, p.928-33, july-aug. 1980.

KELLER, J.; KARMELI, D. Trickle irrigation design parameters. Transactions of the ASAE, v.17, n.2, p.678-84, july-aug.1974.

KELLER, J.; KARMELI, D. Trickle irrigation design. Glendora: Rain Bird Sprinkler Manufaturing Corporation, 1975. 133p.

LENCASTRE, A. Hidráulica geral. Lisboa: Hidroprojecto, 1983. 654p.

MAIA, L.A.F. Desenvolvimento de um software para auxiliar no dimensionamento e manejo da irrigação localizada. Piracicaba, 1994. 158p. Dissertação (M.S.)Escola Superior de Agricultura "Luiz de Queiroz", Universidade de São Paulo. 
MAYERS, L.E.; BUCKS, D.A. Uniform irrigation with low-pressure trickle system. Journal of the Irrigation and Drainage Division, v.100, n.3, p.341-7, sept. 1972.

MORAES, O. Determinação do coeficiente de variação de gotejadores e sua influência na uniformidade de emissão em linhas laterais de irrigação por gotejamento. Piracicaba, 1984. 192p. Dissertação (M.S.)-Escola Superior de Agricultura "Luiz de Queiroz", Universidade de São Paulo.

NAKAYAMA, F.S.; BUCKS, D.A. Trickle irrigation for crop production : Design, operation and manegement. New York: Elsevier, 1986. 383p.

OLITTA, A.F.L. Os métodos de irrigação. São Paulo: Nobel, 1984. 267p.

PARCHOMCHUK, P. Temperature effects on emitter discharge rates. Transactions of the ASAE, v.19, n.2, p.690-2, july-aug. 1976.

PENG, G.F.; WU, I.P.; PHENE, C.J. Temperature effects on drip line hidraulics. Transactions of the ASAE, v.29, n.1, p.211-5, jan-feb. 1986.

PUEYO, L.; FORCADA, J. Cálculo hidráulico - instruções para redes de microaspersão. Item, n.11, p.28-35, dez. 1982.

SAMMIS, T.W.; WU, I.P. Crop yield as effected by irrigation design and management. In:INTERNATIONAL DRIP/TRICKLE IRRIGATION 
CONGRESS, 3., Fresno, California, nov. 1985. Proceedings. St Joseph, 1985. v.1, p.22-8.

SCHMIDT, M.V.V. Características hidráulicas do tubogotejador "Queen Gil". Viçosa, 1995. 43p. Dissertação (M.S.)-Universidade Federal de Viçosa.

SILVA, J.G.F. Características hidráulicas de tubos de polietileno perfurados para irrigação por gotejamento. Viçosa, 1984. 63p. Dissertação (M.S.)-Universidade Federal de Viçosa.

SOARES, A. Características hidráulicas de microtubos Cipla e de linhas laterais para irrigação por gotejamento. Viçosa, 1981. 72p. Dissertação (M.S.)Universidade Federal de Viçosa.

SOIL CONSERVATION SERVICE - USDA. Trickle irrigation, chapter 7, section 15, Irrigation, Washington D.C. 1979. (traft edition)

SOLOMON, K. Manufacturing variation of trickle emitters. Transactions of ASAE, v.22, n.5, p. 1034-8, set-out. 1979.

SOLOMON, K. Global uniformity of trickler. Transactions of ASAE, v.28, n.4, p. 1151-8, july-aug. 1985.

TESTEZLAF, R.; CAMPIONI, E.C. Comportamento hidráulico do tubogotejador "Queen Gil". Engenharia Agrícola, v.13, p. 29-38, 1993. 
VERMEIREN, L.; JOBLING, G. Localized irrigation. Rome: Food and Agriculture Organization of the United Nations, 1980. 203p.

VIEIRA, D.B. Perspectivas do sistema de irrigação por gotejamento em São Paulo. In: SEMINÁRIO NACIONAL DE IRRIGAÇÃO E DRENAGEM, 3. Fortaleza, 1975. Anais. Fortaleza:ABID/DNOCS, 1975. v.3.p.31-3.

WU, I.P.; GITLIN, H.M. Hydraulics and uniformity for drip irrigation. Journal of the Irrigation and Drainage Division, v.99, n.2, p.157-168, 1973.

WU, I.P.; GITLIN, H.M. Drip irrigation design based on uniformity. Transactions of ASAE, v.17, n.1, p. 429-32, jan-feb. 1974a.

WU, I.P.; GITLIN, H.M. Design charts for drip irrigation system. In:INTERNATIONAL DRIP IRRIGATION CONGRESS, 2., Riverside, 1974. Proceedings. Riverside, 1974b. p.293-8.

ZAR, J.H. Biostatistical analysis. 2.ed. Prentice-Hall, Inc., Englewood Cliffs, New Jersey, 1984. p.292-305. 